\title{
Analysis of Time-Dependent Soil Behavior above High-Filled Cut-and-Cover Tunnels Using Discrete Element Method
}

\section{Sheng Li}

Lanzhou Jiaotong University

\section{Guoqiang Han}

Lanzhou Jiaotong University

I-HSUAN HO ( $\square$ ihsuan.ho@und.edu )

University of North Dakota https://orcid.org/0000-0002-7205-8952

\section{Li Ma}

Lanzhou Jiaotong University

\section{Balasingam Muhunthan}

Washington State University

\section{Qicai Wang}

Lanzhou Jiaotong University

\section{Changdan Wang}

Tongji University

\section{Research Article}

Keywords: High-filled cut-and-cover tunnel (HFCCT), discrete element method (DEM), time-dependent, micromechanical properties, vertical earth pressure (VEP)

Posted Date: June 1st, 2021

DOI: https://doi.org/10.21203/rs.3.rs-509520/v1

License: (a) (1) This work is licensed under a Creative Commons Attribution 4.0 International License. Read Full License

Version of Record: A version of this preprint was published at Geotechnical and Geological Engineering on January 17th, 2022. See the published version at https://doi.org/10.1007/s10706-021-02031-3. 


\section{Analysis of Time-Dependent Soil Behavior above High-Filled Cut-and-Cover Tunnels Using Discrete Element Method}

\section{Sheng $\mathrm{Li}^{1}$, Guoqiang $\mathrm{Han}^{2}$, I-Hsuan $\mathrm{Ho}^{3}$, Li Ma ${ }^{4}$, Balasingam Muhunthan ${ }^{5}$, Qicai Wang ${ }^{6}$, Changdan Wang ${ }^{7}$}

${ }^{1}$ Professor, College of Civil Engineering, Lanzhou Jiaotong University, Lanzhou Gansu, 730070, Email: lis@mail.lzjtu.cn.

${ }^{2}$ M.S student, College of Civil Engineering, Lanzhou Jiaotong University, Lanzhou Gansu, 730070, Email: 0218146@stu.lzjtu.edu.cn.

${ }^{3}$ Associate Professor, Harold Hamm School of Geology and Geological Engineering, University of North Dakota, 81 Cornell St. Stop.8358, Grand Forks, ND 58202. Email: ihsuan.ho@und.edu, Corresponding Author

${ }^{4}$ Senior Lecturer, College of Civil Engineering, Lanzhou Institute of Technology, Lanzhou Gansu, 730050, Email: mal@lzit.edu.cn.

${ }^{5}$ Professor, Civil and Environmental Engineering, Washington State University, Email: muhuntha@wsu.edu

${ }^{6}$ Professor, National and Provincial joint Engineering Laboratory of Road \& Bridge Disaster Prevention and control, Lanzhou Jiaotong University, Lanzhou Gansu, 730070, Email: wangqc@mail.lzitu.cn

${ }^{7}$ Associate Professor, Department of Urban Rail Transit and Railway Engineering, College of Transportation Engineering, Tongji University, Shanghai, China 201804, Email: 
2008wangchangdan@tongji.edu.cn.

Abstract: In the Northwest Loess Plateau of China that is full of mountains and deep valleys, high-filled cut-and-cover tunnels (HFCCTs) not only satisfy transportation demands, but they create usable land as well. Several studies have been conducted to investigate the feasibility of HFCCTs, but the time-dependent behavior of the significant backfill needed for HFCCTs has not been adequately examined. Settlement can be severely underestimated due to the time-dependent behavior of ultra-high backfill, and the earth pressure becomes redistributed accordingly. Therefore, the ability to predict the long-term behavior of backfill on HFCCTs is necessary to ensure the long-term safety of the structure. Using a discrete element method (DEM), the changes in vertical earth pressure (VEP), vertical displacement, and load transfer mechanisms above an HFCCT were investigated in this study under scenarios with and without considering backfill creep. The results show that the differential displacement of the soil and the surface settlement obviously increase due to creep and the subsequent cycles of primary and secondary consolidation. Moreover, the stress surrounding the HFCCT is redistributed, causing both the stress concentration and slope effect to weaken over time, but the VEP increases significantly. The micromechanical parameters also change correspondingly. Our results clearly show that the creep of high backfill soil must be considered carefully in HFCCT projects to ensure structural safety.

Keywords: High-filled cut-and-cover tunnel (HFCCT); discrete element method (DEM); timedependent; micromechanical properties; vertical earth pressure (VEP)

\section{Introduction}

The Loess Plateau in China is mountainous and contains deep valleys. The construction of high-filled cut-and-cover tunnels (HFCCTs) in this area is able to satisfy transportation demands and create usable land. Several studies have been conducted on relating to the design of HFCCTs 
especially on the earth pressures sustained by them (Li et al. 2019a, b; 2020a, b, c; Ma et al. 2020), but researchers have not focused enough attention on the creep characteristic of backfill soil of HFCCTs. The backfill soil of HFCCTs is placed over a short time compared to natural soil that has been sedimenting for millions of years, and thus, such backfill soil experiences significant consolidation and creep. The induced relative settlement between the soil column above the HFCCT and both sides of the HFCCT in turn generates additional frictional force or shear stress that can affect the safety and stability of the high-filled structure. Therefore, the ability to predict the long-term behavior of the vertical earth pressure (VEP) above such high-filled structures is necessary.

The earliest studies of high-fill structures focused mainly on pipes and culverts. Based on a series of analytical and experimental work, Marston first proposed a calculation theory for loads on conduits and pipes in trenches (Marston and Anderson 1913; Marston 1930). Then, later researchers employed both numerical simulations and field tests to analyze the mechanical characteristics of pipe culverts to obtain a formula to calculate the VEP on such culverts (Spangler 1950 a, b; Gu et al. 1981; Bennett et al. 2005; Yang 2005; Zheng et al. 2008; Li et al. 2008). Other researchers showed that VEP is highly dependent on the installation conditions that control the magnitude and direction of the pressure on the soil such that the VEP can exceed the geostatic stress in embankment installations (Binger 1947; Spangler 1948; Trollope et al. 1963; Penman et al. 1975; Dasgupta and Sengupta 1991; Yang 2000; Kim and Yoo 2005) while being less than the geostatic stress in trench installations (McGuigan and Valsangkar 2010; Chen and Sun 2014).

Spangler (1973) studied the long-term sustainability of high-filled culverts in terms of changes in earth pressure and settlement over time and observed no significant changes over 21 years when sandy loam topsoil that contains gravel and some light clay was used as backfill soil. 
By testing the changes in earth pressure and deformation over one year, Valestad et al. (1993) showed that the deformation of concrete pipe under high rock fill is small. McAfee and Valsangkar (2008) showed no substantial change in load if the backfill is clayey sand with gravel. In contrast, Sun et al. (2011) found that strain at the bottom of a culvert ceiling, recorded in situ over five years, gradually increased from $<300 \mu \varepsilon$ to $351.29 \mu \varepsilon$ when residual clay was used as backfill. In short, research has shown that the stability of earth pressure on high-filled culverts depends on the creep characteristics of the backfill soil.

Li et al. (2014) conducted a field test of a HFCCT with backfill loess $15 \mathrm{~m}$ above the CCT and found that the VEP above the CCT increased after one year, thus proving that earth pressure varies over time. In addition, earlier studies had found that, when filling with loess in a $90 \mathrm{~m}$ deep valley, the accumulated vertical displacement would be more than $2 \mathrm{~m}$ after six years (Yang et al. 2015; Zhu et al. 2015; Zhang et al. 2018; Ge et al. 2015; Dong et al. 2012; Ming et al. 2018). Such post-construction settlement resulted from both primary consolidation and secondary consolidation (creep). Within the limited observation period, the settlement was mainly from the primary consolidation of the soil. However, to assess the long-term safety of HFCCTs, the timedependent settlement that includes both primary consolidation and secondary consolidation also needs to be considered. A longer period of time-dependent soil settlement is involved with primary consolidation, creep, and the subsequent primary consolidation accompanied by soil creep. The stress redistribution when subjected to soil creep is found to further induce the subsequent cycles of primary and secondary consolidation. Therefore, in addition to primary consolidation, this paper also considers the subsequent creep and the induced cycles of primary and secondary consolidation. The discrete element method (DEM) was employed to study the long-term behavior of soil 
subjected to creep. The results are discussed and can be provided for the long-term considerations of safety for HFCCTs.

\section{Numerical Simulations}

Numerical analysis was conducted in this study using the DEM computer code PFC2D (Particle Flow Code in 2D; Cundall and Strack 1999) to investigate the variations in VEP and vertical displacement and to discuss the load transfer mechanisms above the HFCCT that result from backfill soil creep over time in terms of porosity, coordination number, and contact force chain.

\subsection{Model establishment}

Fig. 1 presents a typical DEM model that was used in this study. In this model, the backfill soil is loess with a relative compaction of $R=90 \%$, cohesion of $c=58 \mathrm{kPa}$, and internal friction angle of $\varphi=30^{\circ}$. The backfill soil is layered with in an inverted trapezoidal trench that has a slope angle of $70^{\circ}$. The height of the trench is $41 \mathrm{~m}$, the height of the CCT is $11 \mathrm{~m}$, and the height of the backfill soil above the CCT is $30 \mathrm{~m}$. The bottom widths of the trench and the CCT are $13.8 \mathrm{~m}$ and $12.8 \mathrm{~m}$, respectively. The backfill soil is divided into seven layers; Layer_1 to Layer_6 are above the CCT (from the top of the CCT to the surface) and both sides of the CCT are defined as a lateral layer. The backfill soil was simulated using ball particles from $10 \mathrm{~cm}$ to $20 \mathrm{~cm}$ in diameter. To reduce the horizontal stress when the initial model is generated, an improved multi-layer compaction method (Lai et al. 2014) was used to generate a loose soil particle assembly, as follows:

Step 1: Generate particles in the lateral layer (using the ball distribute command) with the specified initial porosity (denoted as NI) and then cycle enough steps to obtain particles to be calculated to achieve equilibrium. 
Step 2: Compress the particles by moving the wall downwards until the porosity of the lateral layer reaches the target porosity (denoted as NT). In this process, the particle friction coefficient is set to 0 , the gravitational acceleration is set to $g$, and NI $>$ NT.

Step 3: Create a new wall above the lateral layer and then generate the first layer of particles in this new area according to Steps 1 and 2 and compress the particles. When the compression process is complete, delete the wall below the first layer and cycle enough steps until the particle system is balanced again.

Step 4: Generate Layer_2 to Layer_6 in sequence by repeating Step 3. Then, execute enough steps until the whole model reaches initial equilibrium.

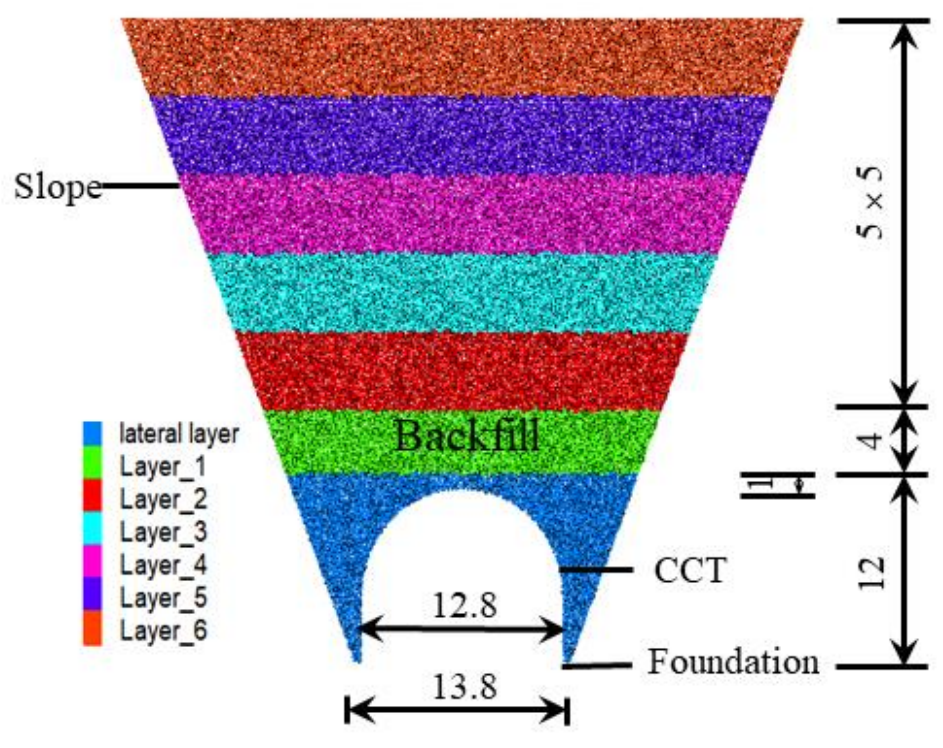

Fig. 1 Discrete element model for HFCCT (unit: m).

To ensure that the relative compaction of each layer reaches $R=90 \%$, measurement circles were set in each layer to track the compaction. Further, a series of measurement circles was arranged above the CCT to measure the variations in VEP, vertical displacement, porosity, and the coordination number at specific locations over time. Specifically, the measurement circles at 
Section B-B monitor the VEP on top of the CCT; the measurement circles in each layer (from AA to $\mathrm{H}-\mathrm{H}$ ) monitor the vertical displacement above the CCT; and the red measurement circles at Sections I-I and J-J simultaneously monitor the porosity and coordination number of the different layers above the CCT. Fig. 2 shows the locations of the measurement circles and some important model dimensions.

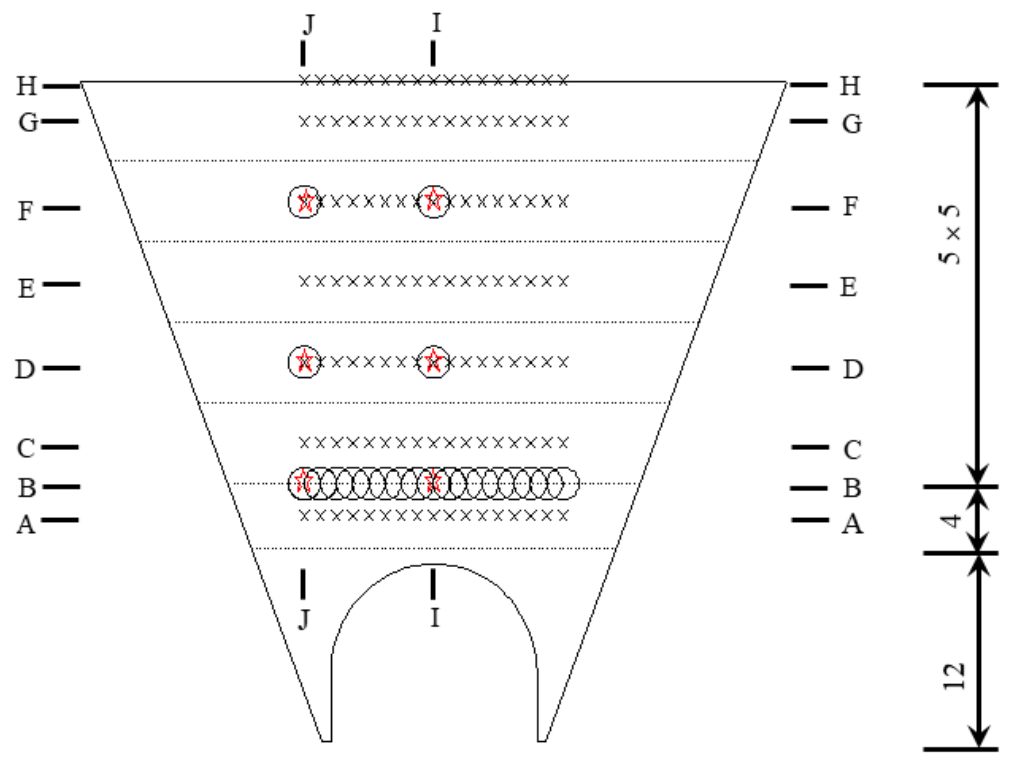

Earth pressure measurement circle; $\times$ displacement measurement circle; porosity and coordination number measurement circle

Fig. 2 Arrangement of measurement circles in model (unit: m).

\subsection{Selection of creep model}

Zhang et al. (2018) selected loess (1.0 $\mathrm{m}$ to $1.5 \mathrm{~m}$ underground) as a test soil sample in their study. The samples contained silt and a little silt clay. Table 1 lists the physical properties of these loess samples. 
Table 1. Physical Properties of Loess Samples (Zhang et al. 2018)

\begin{tabular}{cccccc}
\hline Optimum & Maximum & & & Plasticity & \\
moisture & dry unit & Liquid limit & Plastic limit & index & Specific gravity \\
content & weight & $\left(\mathrm{W}_{\mathrm{L}}, \%\right)$ & $\left(\mathrm{W}_{\mathrm{P}}, \%\right)$ & $(\mathrm{I})$ & \\
$\left(\omega_{0}, \%\right)$ & $\left(\rho_{\mathrm{d}}, \mathrm{g} / \mathrm{cm} 3\right)$ & & & & \\
\hline 15.7 & 1.78 & 26.9 & 19.8 & 7.1 & 2.71 \\
\hline
\end{tabular}

Subsequently, Zhang et al. (2018) conducted a series of one-dimensional compression creep tests and obtained the strain-time curves of loess under different pressure levels. Then, Zhang et al. (2018) used three constitutive models, the Burgers model, logarithmic model, and power function model, to fit the strain-time curves obtained from the tests. A comparison of the three constitutive models showed that the Burgers model was the best fit. Moreover, several other researchers (Zhu and Li 2015; Ge et al. 2015; Ou et al. 2019; Chen et al. 2020) conducted similar experiments on loess and also found that the Burgers model fit their experimental data well. So, the Burgers model was used in this study to simulate backfill creep. The Burgers model simulates creep mechanisms by using a Kelvin model and a Maxwell model. The constitutive equation for strain is shown here as Equation (1).

$$
\varepsilon(t)=\frac{\sigma_{0}}{E_{M}}+\frac{\sigma_{0}}{\eta_{M}} t+\frac{\sigma_{0}}{E_{k}}\left[1-\exp \left(-\frac{E_{k}}{\eta_{K}} t\right)\right]
$$

where $\sigma_{0}$ is the initial stress; $E_{\mathrm{k}}$ is the elasticity of the Kelvin model; $\eta_{\mathrm{k}}$ is the viscosity of the Kelvin model; $E_{\mathrm{M}}$ is the elasticity of the Maxwell model; $\eta_{\mathrm{M}}$ is the viscosity of the Maxwell model; $t$ is creep time, and $\varepsilon(t)$ is strain. 
Zhang et al. (2018) obtained the loess' (moisture content of 15\%, relative compaction of 90\%) macro-parameters of the Burgers model under different stress conditions, as shown in Table 2. Details regarding the macro-parameter acquisition process can be found in Zhang et al. (2018).

Table 2 Macro-Parameters of Loess Used in Burgers Model (Zhang et al. 2018)

\begin{tabular}{|c|c|c|c|c|c|}
\hline $\begin{array}{l}\text { Stress } \\
\left(\sigma_{0}, \mathrm{kPa}\right)\end{array}$ & $\begin{array}{c}\text { Maxwell elasticity } \\
\left(E_{\mathrm{M}}, \mathrm{MPa}\right)\end{array}$ & $\begin{array}{l}\text { Kelvin elasticity } \\
\qquad\left(E_{\mathrm{K}}, \mathrm{MPa}\right)\end{array}$ & $\begin{array}{c}\text { Maxwell viscosity } \\
\left(\eta_{\mathrm{M}}, \mathrm{MPa} \cdot \mathrm{h}\right)\end{array}$ & $\begin{array}{c}\text { Kelvin } \\
\text { viscosity } \\
\left(\eta_{\mathrm{K}}, \mathrm{MPa} \cdot \mathrm{h}\right)\end{array}$ & $\begin{array}{c}\text { Coefficient of } \\
\text { determination } \\
\left(R^{2}\right)\end{array}$ \\
\hline 100 & 18.6 & 286.87 & 2221.09 & 686.37 & 0.9973 \\
\hline 200 & 26.62 & 122.25 & 4079.17 & 70.57 & 0.9944 \\
\hline 400 & 19.9 & 58.73 & 6297.69 & 23.61 & 0.9913 \\
\hline 800 & 17.79 & 117.8 & 18399 & 32.6 & 0.9875 \\
\hline 1200 & 14.98 & 122.08 & 31180.3 & 86.51 & 0.9536 \\
\hline 1600 & 21.32 & 165.47 & 48099.4 & 317.064 & 0.9570 \\
\hline
\end{tabular}

Fig. 3 shows that, two directional micro-parameters, the normal and shear directions in the PFC2D model, always correspond to the one macro-parameter. (Particle Flow Code 5.0 numerical simulation technology and application; Shi et al. 2018). 


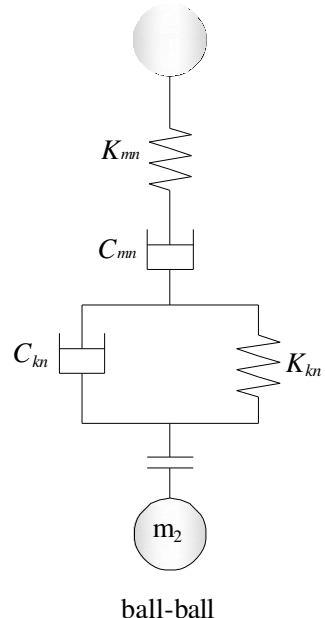

(a)

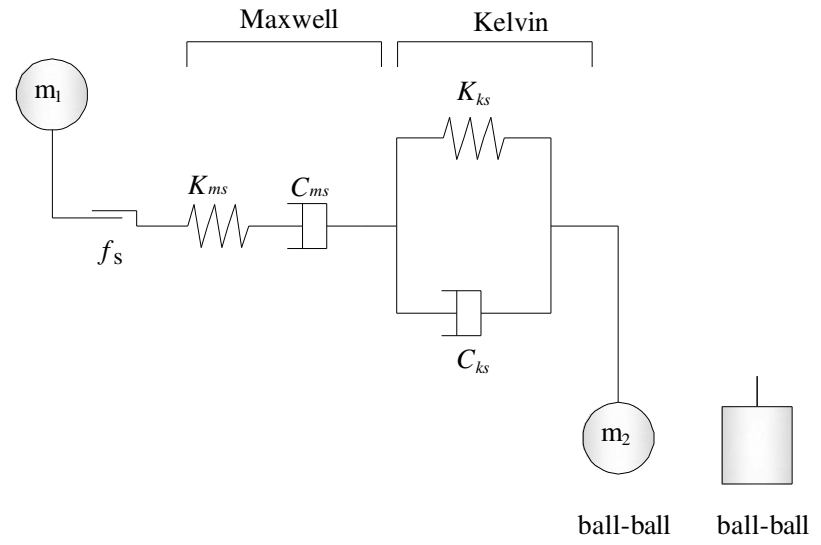

(b)

Fig. 3 Burgers contact model in PFC2D: (a) normal direction and (b) shear direction.

Notes: In Fig. 3, $K_{m n}$ and $K_{m s}$ correspond respectively to the normal and shear stiffness of the Maxwell section; $C_{m n}$ and $C_{m s}$ correspond respectively to the normal and shear viscosity of the Maxwell section; $K_{k n}$ and $K_{k s}$ correspond respectively to the normal and shear stiffness of the Kelvin section; $C_{k n}$ and $C_{k s}$ correspond respectively to the normal and shear viscosity of the Kelvin section; and $f_{s}$ is the friction coefficient.

\subsection{Material parameters}

This paper adopts the macro-parameters presented in Table 2 as the source data to conduct the numerical simulations. However, because the magnitudes of earth pressure used in this paper are not consistent with those reported in Zhang et al. (2018), the macro-parameters in Table 2 could not be applied directly in this study. Therefore, numerical interpolation and fitting are used to 
obtain the required macro-parameters that correspond to the magnitudes of the earth pressure in this paper (see Table 4).

The numerical simulations that use PFC2D software are based on the micro-parameters of the soil because the software program cannot identify the macro-parameters. Therefore, a numerical biaxial compression test model was established to calibrate the micro-parameters of the soil. This model uses inversion trial calculation to continuously adjust the micro-parameters that control the soil's characteristics until the mechanical characteristics of the macro- and micro-parameters correspond to each other. The width and height of the biaxial compression test model are $1200 \mathrm{~cm}$ and $2400 \mathrm{~cm}$, respectively, and the particle sizes are from $10 \mathrm{~cm}$ to $20 \mathrm{~cm}$ in diameter. The specific calibration process is as follows.

Step 1: Calibrate the micro-parameters of the backfill soil (without considering creep) according to the macro-parameters (Zhang et al. 2018) of loess using the numerical biaxial compression test model. The specific method used for this parameter calibration was introduced in Li et al. (2019a). Table 3 shows the micro-parameters of the backfill soil without considering creep. Fig. 4 shows a partial comparison between the DEM results and the Zhang et al. (2018) results without considering creep.

Table 3 Micro-Parameters of Backfill Soil without Considering Creep

\begin{tabular}{|c|c|c|c|c|c|c|c|c|}
\hline & Diameter & & & & & & Normal & \\
\hline $\begin{array}{c}\text { Micro- } \\
\text { parameters }\end{array}$ & $\begin{array}{c}\text { of } \\
\text { particles } \\
\text { (cm) }\end{array}$ & Porosity & $\begin{array}{l}\text { Density } \\
\left(\mathrm{kg} / \mathrm{m}^{3}\right)\end{array}$ & $\begin{array}{l}\text { Normal } \\
\text { stiffness } \\
(\mathrm{N} / \mathrm{m})\end{array}$ & $\begin{array}{c}\text { Tangential } \\
\text { stiffness } \\
(\mathrm{N} / \mathrm{m})\end{array}$ & $\begin{array}{c}\text { Friction } \\
\text { coefficient }\end{array}$ & $\begin{array}{c}\text { bond } \\
\text { strength } \\
\text { (N) }\end{array}$ & $\begin{array}{c}\text { Tangential } \\
\text { bond } \\
\text { strength }(\mathrm{N})\end{array}$ \\
\hline $\begin{array}{c}\text { Backfill } \\
\text { soil }\end{array}$ & $10-20$ & 0.1 & 1800 & $2 \mathrm{e} 8$ & $1 \mathrm{e} 8$ & 1.6 & 900 & 900 \\
\hline
\end{tabular}




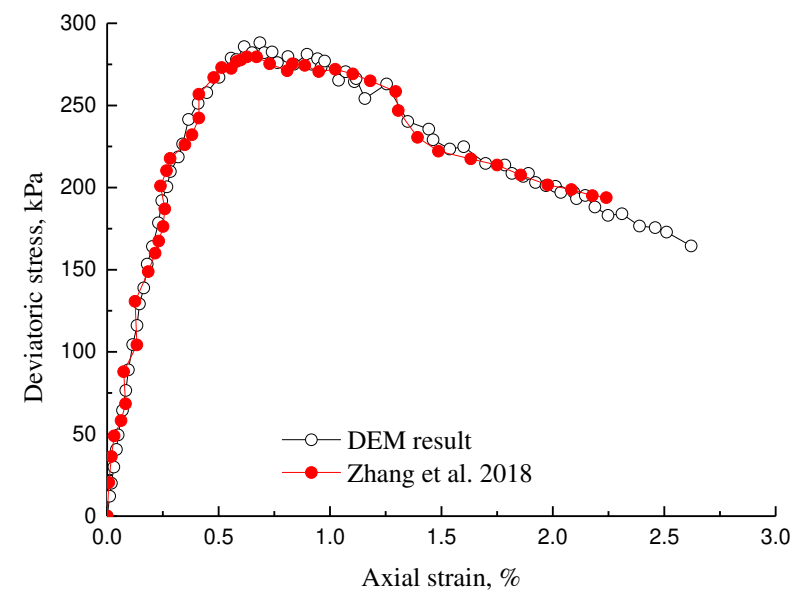

(a)

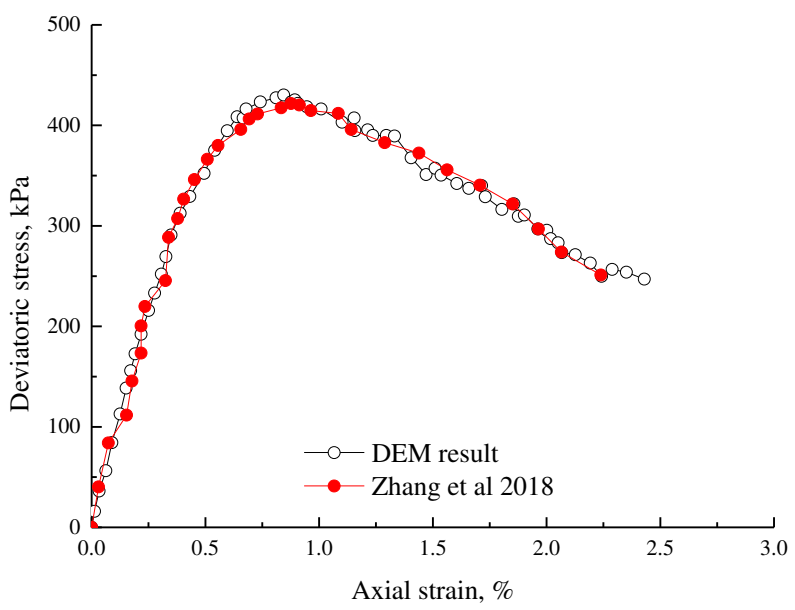

(b)

Fig. 4 Comparison of DEM and Zhang et al. (2018) results for confining stress: (a) $50 \mathrm{kPa}$ and (b) $100 \mathrm{kPa}$.

Step 2: Assign the micro-parameters of the backfill soil without considering creep to the model (Fig. 1) using FISH (a built-in programming code) to obtain the initial earth pressure (the instantaneous earth pressure after the backfill was completed but the creep had not started) after the equilibrium of model is achieved.

Step 3: Based on the macro-parameters of loess presented in Table 2, obtain the macroparameters for the Burgers model, shown in Table 4, that correspond to the initial earth pressure obtained in Step 2 through interpolation and fitting.

Table 4 Macro-Parameters for Burgers Model under Initial Earth Pressure

$\begin{array}{cccccc}\text { Stress } & \text { Maxwell } & \text { Kelvin } & \text { Maxwell } & \text { Kelvin } & \text { Coefficient of } \\ \left(\sigma_{0}, \mathrm{kPa}\right) & \text { elasticity } & \text { elasticity } & \text { viscosity } & \text { viscosity } & \text { determination } \\ & \left(E_{M}, \mathrm{MPa}\right) & \left(E_{\mathrm{K}}, \mathrm{MPa}\right) & \left(\eta_{\mathrm{M}}, \mathrm{MPa} \cdot \mathrm{h}\right) & \left(\eta_{\mathrm{K}}, \mathrm{MPa} \cdot \mathrm{h}\right) & \left(R^{2}\right)\end{array}$




\begin{tabular}{llllll}
\hline 250 & 12.24 & 26.70 & 26097.37 & 15.62 & 0.9751 \\
330 & 13.29 & 25.58 & 16626.21 & 8.84 & 0.9750 \\
300 & 12.98 & 25.94 & 20576.85 & 11.05 & 0.9793 \\
265 & 12.68 & 25.88 & 25843.71 & 14.63 & 0.9660 \\
200 & 11.76 & 26.25 & 33002.28 & 21.32 & 0.9686 \\
110 & 10.25 & 19.80 & 12281.87 & 9.86 & 0.9887 \\
40 & 9.11 & 14.47 & 1320.80 & 0.86 & 0.9976
\end{tabular}

Step 4: Substitute the initial earth pressure and corresponding macro-parameters (Table 4) into the Burgers constitutive equation (Equation (1)). Use post-processing software to iteratively calculate the strain under earth pressure at different times.

Step 5: Establish the Burgers numerical biaxial compression test model to calibrate the microparameters of the backfill soil with considering creep.

In PFC2D, the micro-parameters in two directions, i.e., the normal and shear directions, always correspond to the one macro-parameter (Table 4). First, a set of initial micro-parameters is assumed based on empirical values. Then, the micro-parameters are adjusted continuously until the strain-time curves of the test model under different initial earth pressure levels basically fit those curves in Step 4 that are regarded as appropriate and acceptable. Table 5 shows the microparameters of the Burgers model under different initial earth pressure levels. Fig. 5 shows a comparison of the partial strain-time curves of the DEM results and Zhang et al. (2018) results under initial earth pressure levels.

Table 5 Micro-Parameters of Burgers Model under Different Earth Pressure Levels

\begin{tabular}{cccccccccc}
\hline Stress & $K_{k n}$ & $K_{k s}$ & $C_{k n}$ & $C_{k s}$ & $K_{m n}$ & $K_{m s}$ & $C_{m n}$ & $C m s$ & $f_{s}$ \\
$\left(\sigma_{0}, \mathrm{kPa}\right)$ & & & & & & & & \\
\hline
\end{tabular}




\begin{tabular}{llllllllll}
\hline 250 & $5.0 \mathrm{E}+9$ & $5.0 \mathrm{E}+9$ & $1.0 \mathrm{E}+10$ & $1.0 \mathrm{E}+10$ & $5.5 \mathrm{E}+6$ & $5.5 \mathrm{E}+6$ & $1.0 \mathrm{E}+30$ & $1.0 \mathrm{E}+30$ & 0.54 \\
330 & $5.0 \mathrm{E}+9$ & $5.0 \mathrm{E}+9$ & $1.0 \mathrm{E}+10$ & $1.0 \mathrm{E}+10$ & $7.0 \mathrm{E}+6$ & $7.0 \mathrm{E}+6$ & $1.0 \mathrm{E}+30$ & $1.0 \mathrm{E}+30$ & 0.56 \\
300 & $5.0 \mathrm{E}+9$ & $5.0 \mathrm{E}+9$ & $1.0 \mathrm{E}+10$ & $1.0 \mathrm{E}+10$ & $6.5 \mathrm{E}+6$ & $6.5 \mathrm{E}+6$ & $1.0 \mathrm{E}+30$ & $1.0 \mathrm{E}+30$ & 0.56 \\
265 & $5.0 \mathrm{E}+9$ & $5.0 \mathrm{E}+9$ & $1.0 \mathrm{E}+10$ & $1.0 \mathrm{E}+10$ & $6.0 \mathrm{E}+6$ & $6.0 \mathrm{E}+6$ & $1.0 \mathrm{E}+30$ & $1.0 \mathrm{E}+30$ & 0.54 \\
200 & $5.0 \mathrm{E}+9$ & $5.0 \mathrm{E}+9$ & $1.0 \mathrm{E}+10$ & $1.0 \mathrm{E}+10$ & $4.5 \mathrm{E}+6$ & $4.5 \mathrm{E}+6$ & $1.0 \mathrm{E}+30$ & $1.0 \mathrm{E}+30$ & 0.44 \\
110 & $1.2 \mathrm{E}+9$ & $1.2 \mathrm{E}+9$ & $1.0 \mathrm{E}+10$ & $1.0 \mathrm{E}+10$ & $1.5 \mathrm{E}+06$ & $1.5 \mathrm{E}+6$ & $1.0 \mathrm{E}+30$ & $1.0 \mathrm{E}+30$ & 0.30 \\
40 & $1.0 \mathrm{E}+9$ & $1.0 \mathrm{E}+9$ & $1.0 \mathrm{E}+10$ & $1.0 \mathrm{E}+10$ & $1.0 \mathrm{E}+06$ & $1.0 \mathrm{E}+6$ & $1.0 \mathrm{E}+30$ & $1.0 \mathrm{E}+30$ & 0.28 \\
\hline
\end{tabular}

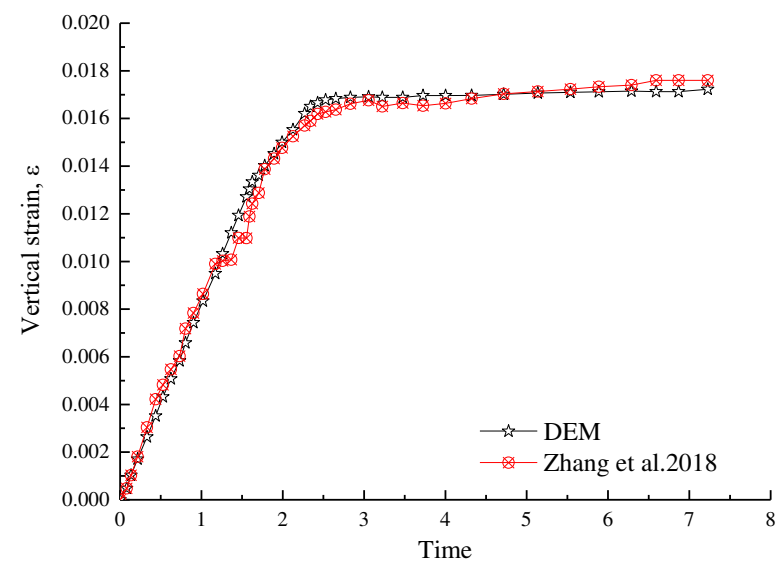

(a)

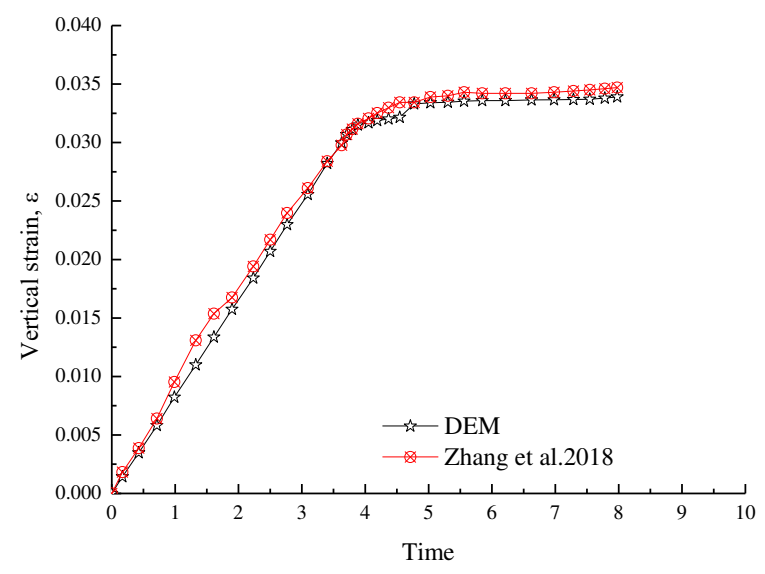

(c)

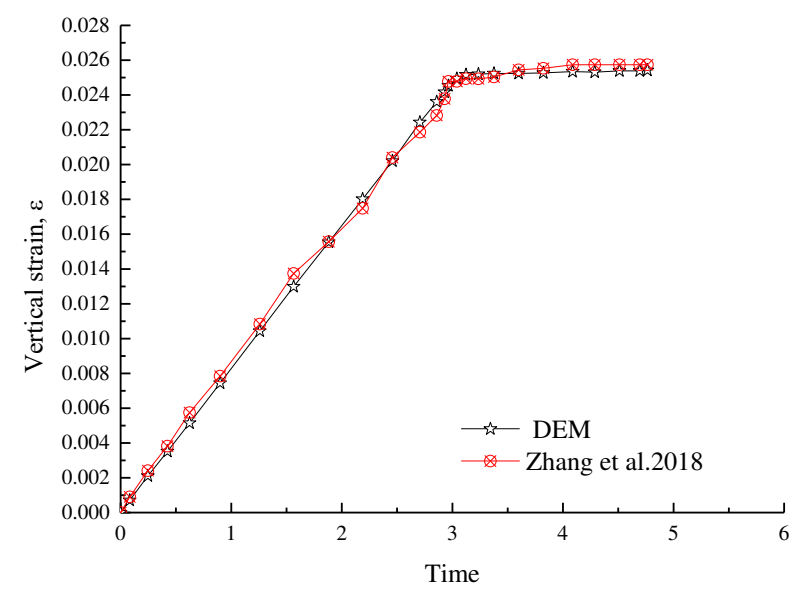

(b)

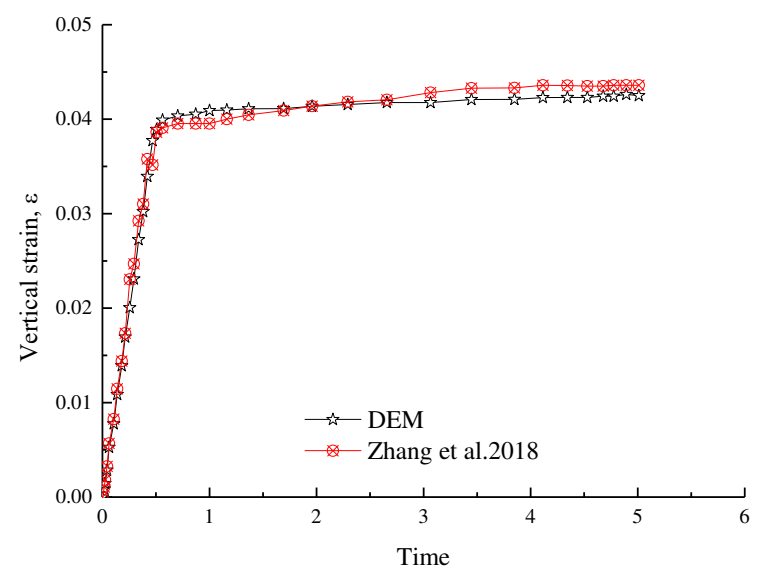

(d) 
Fig. 5 Comparison of DEM and Zhang et al. (2018) results under partial initial earth pressure:

(a) $110 \mathrm{kPa}$, (b) $200 \mathrm{kPa}$, (c) $265 \mathrm{kPa}$, and (d) $330 \mathrm{kPa}$.

Note that Step 1 through Step 5 produce only a set of micro-parameters under creep. However, due to the variation in earth pressure that results from the creep of the backfill soil at different stages, the micro-parameters of the Burgers model at different stages will change accordingly, and new micro-parameters must be assigned to the backfill soil.

Step 6: Use the FISH program that is embedded in PFC2D to repeat Step 2 through Step 5 to obtain the new micro-parameters of the backfill soil under different earth pressure levels at different stages and redistribute them to the corresponding layers.

For the simulations, the Linear Contact Bond Model was selected to simulate the contact properties among the soil particles in the case without considering the creep of backfill soil. In the case that considers creep, the contact properties among the soil particles were simulated by the Burgers model. The Linear Contact Bond Model was selected to simulate the contact properties between the soil particles and the wall. In addition, the slopes, foundation, and CCT were simulated by the wall, given that the deformation of the foundation and CCT was much smaller than that of the backfill; that is, the wall that simulated the foundation and the CCT could be regarded as completely rigid ( $\mathrm{Li}$ et al. 2020b). The shear stiffness and normal stiffness of the foundation and CCT were set to $10^{10} \mathrm{~N} / \mathrm{m}$, which is much greater than the shear stiffness and normal stiffness of the backfill, in the simulation. The stiffness of the wall that simulates the slopes was set to be ten times the stiffness of the backfill. Due to the fact that the total cycle step was up to 300,000 when the model reached equilibrium in this numerical stimulation, the total step was divided into 10 stages to facilitate the analysis of the variation over time. 


\section{Results}

\subsection{Analysis of vertical earth pressure}

\subsubsection{Vertical earth pressure distribution above CCT}

Fig. 6 shows the distribution of VEP without considering the creep of the backfill soil, with considering the creep of the backfill soil, and the geostatic conditions ( $\gamma h$, where $\gamma$ is the unit weight of the backfill, $\mathrm{kN} / \mathrm{m}^{3}$, and $h$ is the height of the backfill above the CCT, $\mathrm{m}$ ) through Section B-B. When the creep of the backfill soil is not considered, the distribution of the VEP above the CCT has an inverted ' $\mathrm{V}$ ' shape due to the stress concentration, which yields a maximum difference in VEP between the axis and sides of the CCT. Moreover, the VEP is less than $\gamma h$ because of the effect of the slope. These findings are consistent with previous research ( $\mathrm{Li}$ et al. 2019a, b). However, the VEP change over time due to the position of the particles is constantly being adjusted. After the soil creep becomes stable, the VEP at Section B-B at the axis and on both sides of the CCT reaches $463 \mathrm{kPa}$ and $450 \mathrm{kPa}$, respectively, and the difference between the VEP at the axis of the CCT and $\gamma h$ is just $2.8 \%$, which is almost equivalent to the geostatic stress. This outcome indicates that the VEP will be redistributed over time in cases of high backfill soil with creep. Both the stress concentration and the slope effect weaken over time, causing the VEP above the CCT to eventually equilibrate with the geostatic stress. 


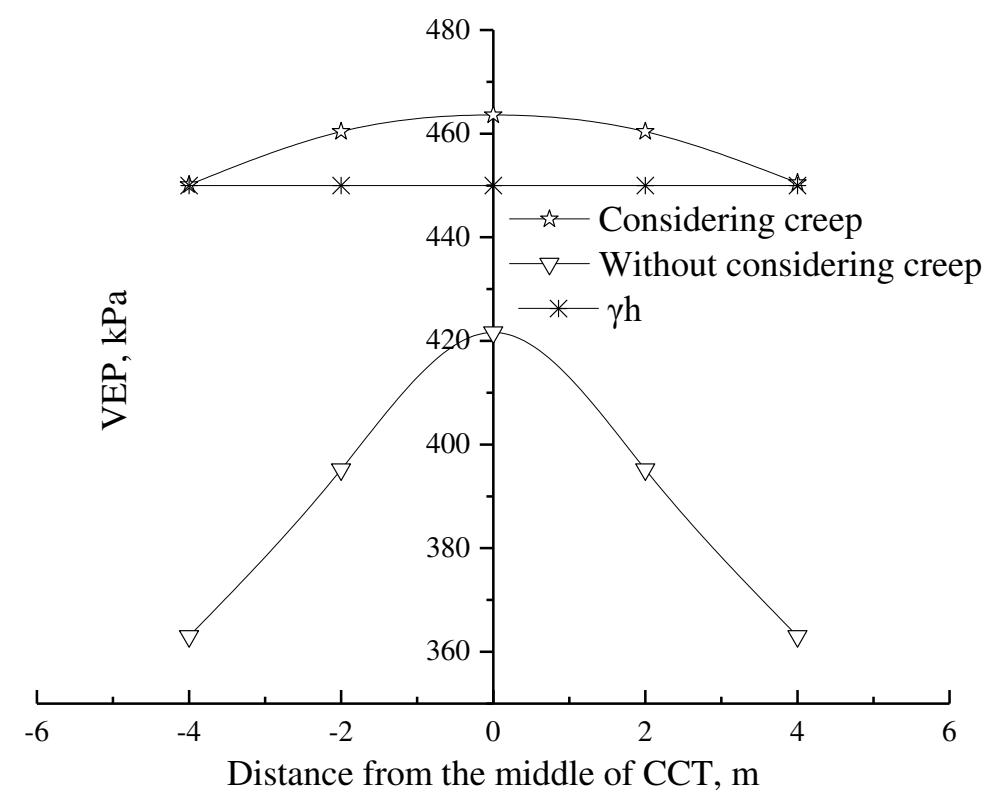

Fig. 6 Vertical earth pressure distribution at Section B-B.

\subsubsection{Variation of earth pressure with time}

Fig. 7 shows the variation in VEP over time in Layer_1, Layer_3, and Layer_5 at Section II (Fig. 2). The VEP of each layer changes obviously in the initial stages (from Stage 1 to Stage 4) and tends to stabilize after Stage 4. The VEP then rebounds between Stage 2 and Stage 4 due to the particles' adaptive ability at the micro level whereby the contacts and interaction effects (nesting and biting) among the particles under the earth pressure tend to adjust to a balanced state, which results in the stress redistribution. Moreover, the VEP always exceeds $\gamma h$ during the initial stage of creep and eventually stabilizes at values close to $\gamma h$ after Stage 4 . Therefore, the maximum VEP during the initial stages of creep should be considered carefully in HFCCT construction design. Meanwhile, the maximum increment of the VEP is evident in Layer_1 due to the greater earth pressure. 


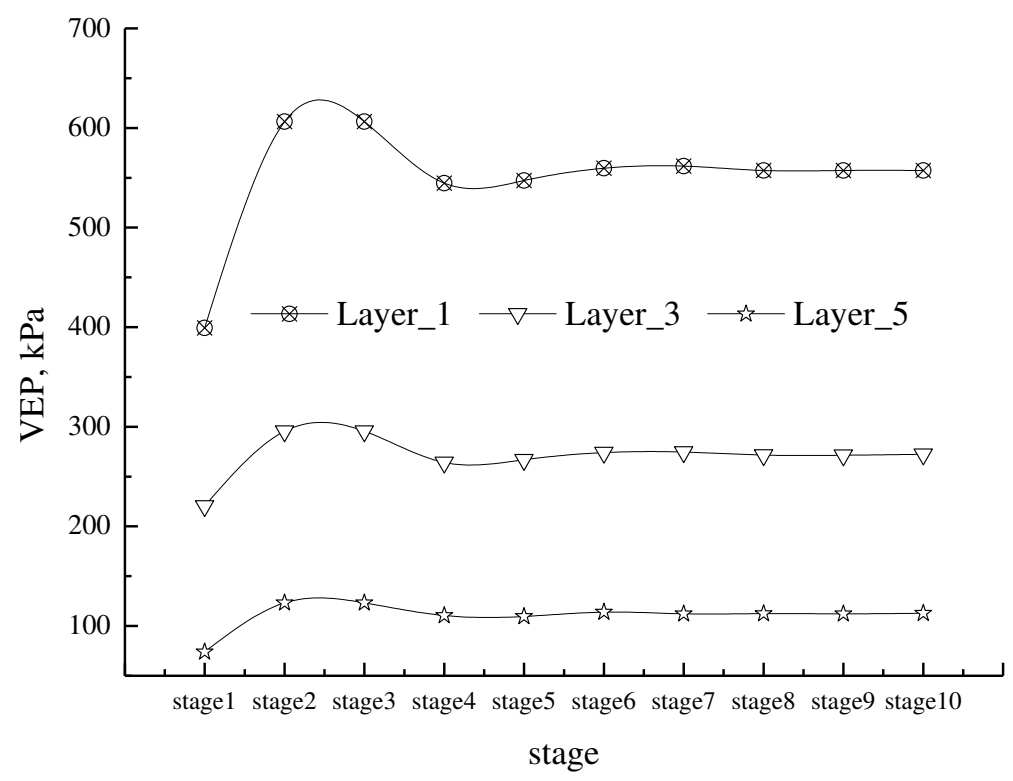

Fig. 7 Vertical earth pressure in different layers at Section I-I over time.

\subsection{Analysis of displacement}

\subsubsection{Variation of displacement over time}

Fig. 8 presents particle vertical displacement nephrograms of the backfill soil at different stages. Fig. 8 (a) shows that, when the creep of the backfill soil is not considered, arched displacement of the backfill soil on top of the CCT is not evident, and the maximum settlement locates at the middle of Layer_6. When the creep of the backfill soil is considered, the arched displacement of the backfill soil on top of the CCT is gradually obvious, and the maximum vertical displacement expands laterally over time to the entire Layer_6. 


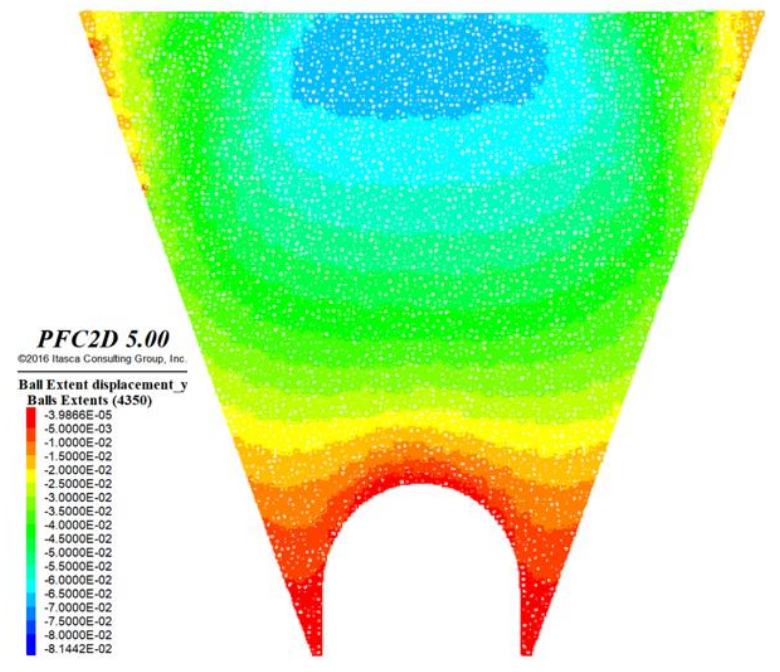

(a)

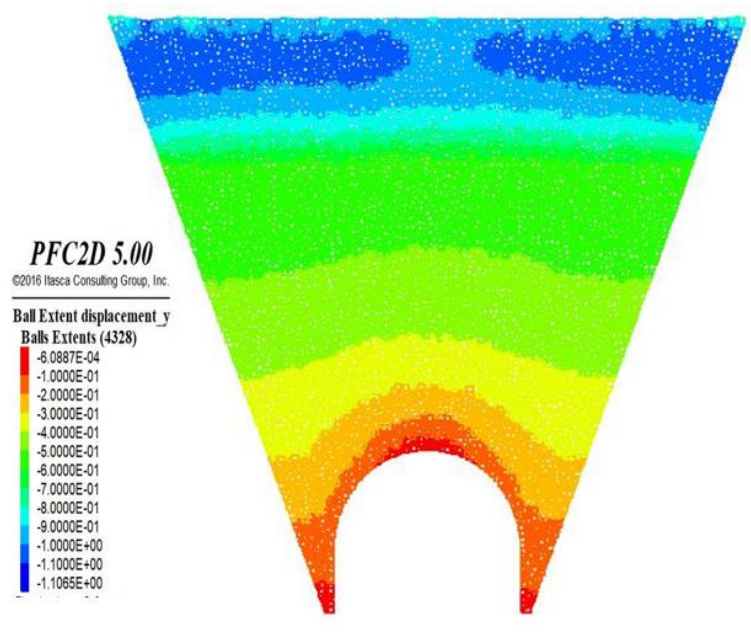

(c)

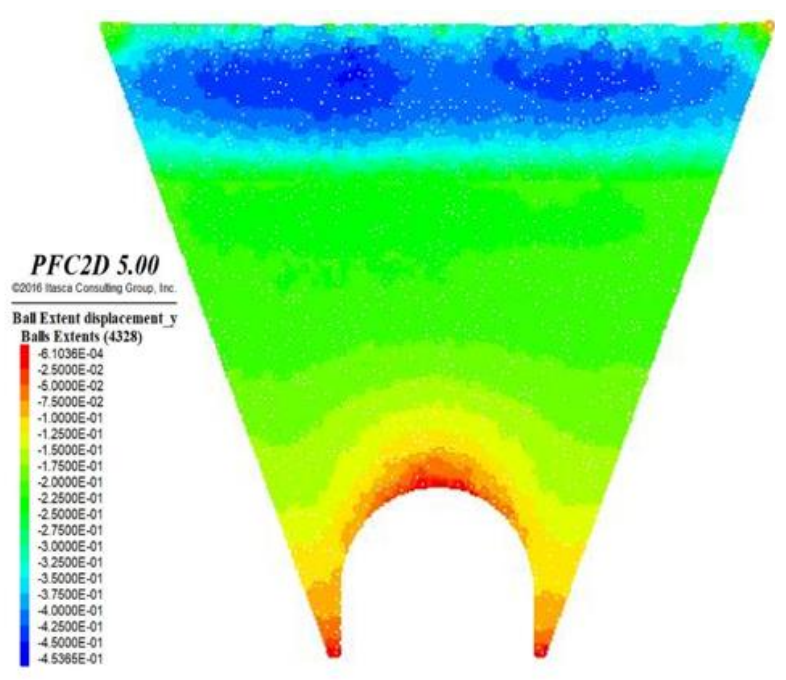

(b)

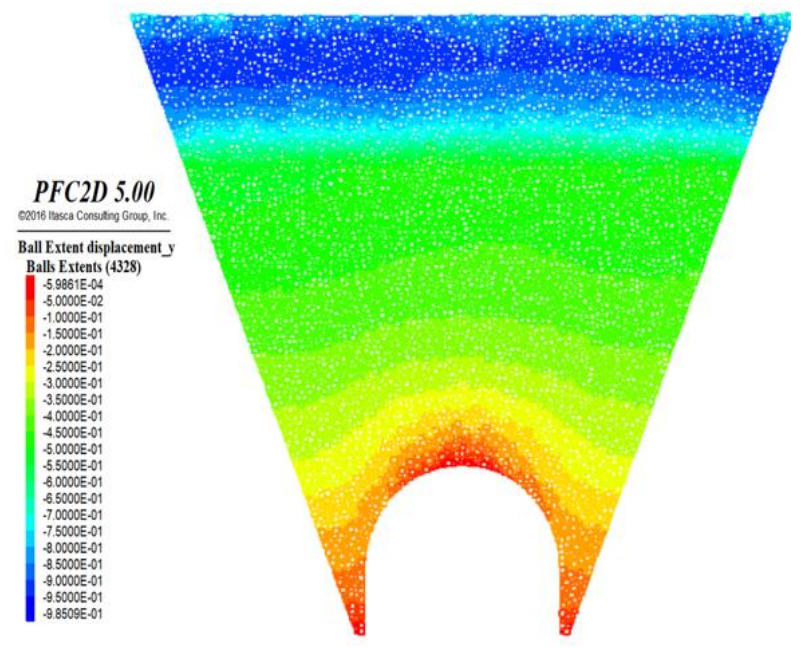

(d)

Fig. 8 Vertical displacement nephrograms of backfill soil: (a) without considering creep of backfill soil; and creep stages at (b) Stage 1, (c) Stage 3, and (d) Stage 10.

Fig. 9 shows the variation in vertical displacement over time in Layer_1, Layer_3, and Layer_5 at Sections I-I and J-J (Fig. 2), which corresponds with that of the VEP. In addition, the vertical displacement at Section J-J is always greater than at Section I-I, especially in Layer_1, which explains the evolution law of the vertical displacement nephrograms presented in Fig. 8. 
This outcome is due to the stiffness difference between the CCT and the backfill soil on both sides of the CCT. Moreover, the rebound of the vertical displacement curves (from Stage 2 to Stage 4) in each layer corresponds to the rebound of the VEP.

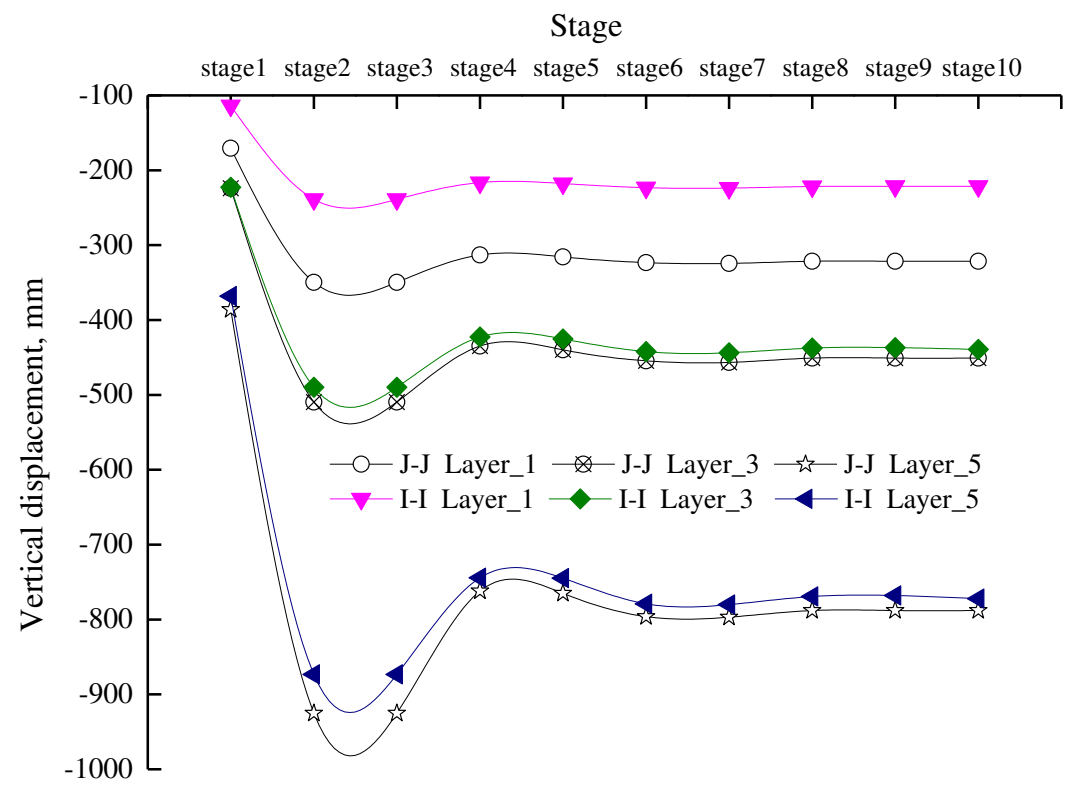

Fig. 9 Vertical displacement in different layers at Sections I-I and J-J over time.

\subsubsection{Vertical displacement distribution on top of HFCCT}

Fig. 10 shows the effect of creep on the vertical displacement of the backfill soil at Section A-A (on top of the CCT; see Fig. 2). When the creep of the backfill soil is not considered, the vertical displacement at Section A-A is almost uniform. The minimum displacement (along the CCT's axis) and the maximum displacement (adjacent to the CCT) are $-13.18 \mathrm{~mm}$ and $-20.4 \mathrm{~mm}$, respectively. The difference is only $7.22 \mathrm{~mm}$. After the creep of the backfill soil becomes stable, the vertical displacement reaches $-155.62 \mathrm{~mm}$ along the CCT axis and $-305.18 \mathrm{~mm}$ adjacent to the CCT, respectively. Clearly, the vertical displacement increases due to the creep of the backfill 
soil. The vertical displacement that results from the creep accounts for $93 \%$ of the total displacement. Moreover, the vertical displacement of the backfill soil in Section A-A has an obvious inverted ' $\mathrm{V}$ ' shape when the creep is stable, which is attributable to the greater stiffness of the CCT, which in turn leads to non-uniform settlement.

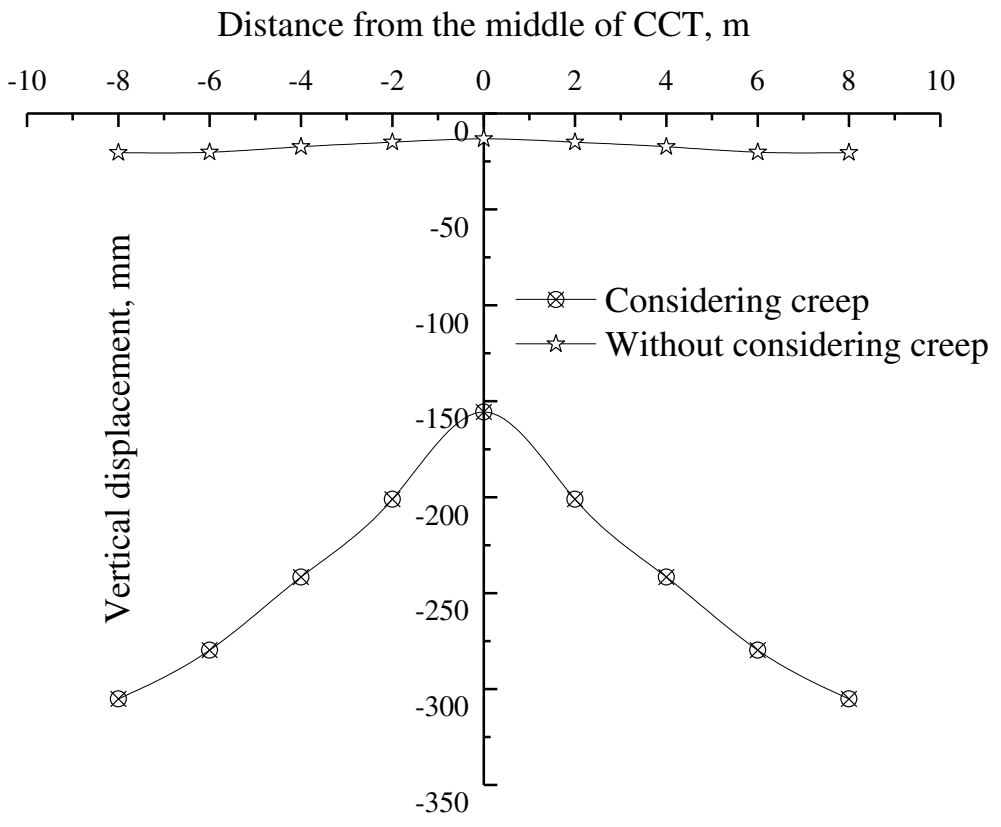

Fig. 10 Vertical displacement at Section A-A.

In order to study the variation in the vertical displacement of the soil in each layer above the CCT, the soil's vertical displacement from Layer_1 (Section A-A) to Layer_6 (Section G-G) was recorded, as presented in Fig. 11. The changes in vertical displacement at each layer above the CCT are similar in cases with and without consideration of backfill soil creep, although the vertical displacement values are different. Moreover, the vertical displacement is less at the axis of the CCT than at both sides due to the greater stiffness of the CCT in Layer_1, whereas it becomes uniform from Layer_2 to Layer_6 because the influence of CCT's stiffness diminishes gradually. When the creep of the backfill soil is not considered, the displacement values increase from -17.8 
$\mathrm{mm}$ at Layer_1 to $-67.5 \mathrm{~mm}$ at Layer_6 along the CCT axis. When the creep of the backfill soil is considered, the displacement values increase from $-222.2 \mathrm{~mm}$ at Layer_1 to $-901.5 \mathrm{~mm}$ at Layer_6 along the CCT axis. The vertical displacement increment at each layer is obvious over time. Clearly, the vertical displacement of each layer develops with the creep of the backfill soil, which leads to stress redistribution above the CCT. Therefore, this phenomenon requires careful engineering attention to avoid structural damage.

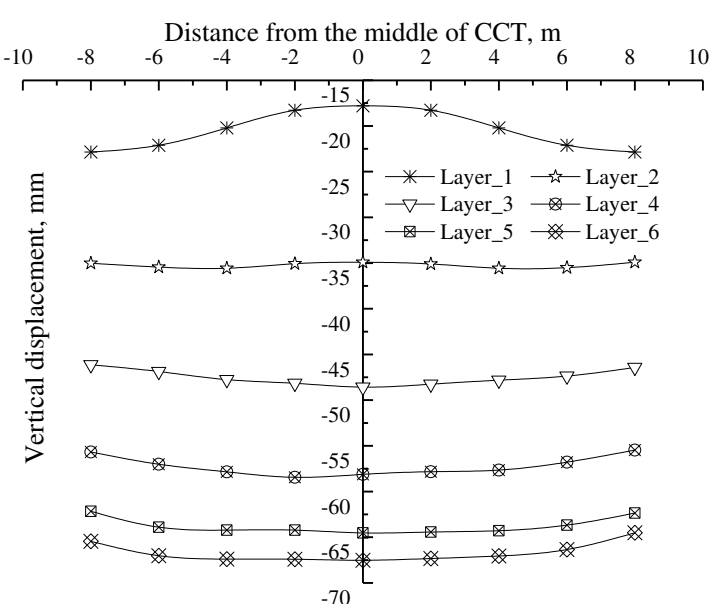

(a)

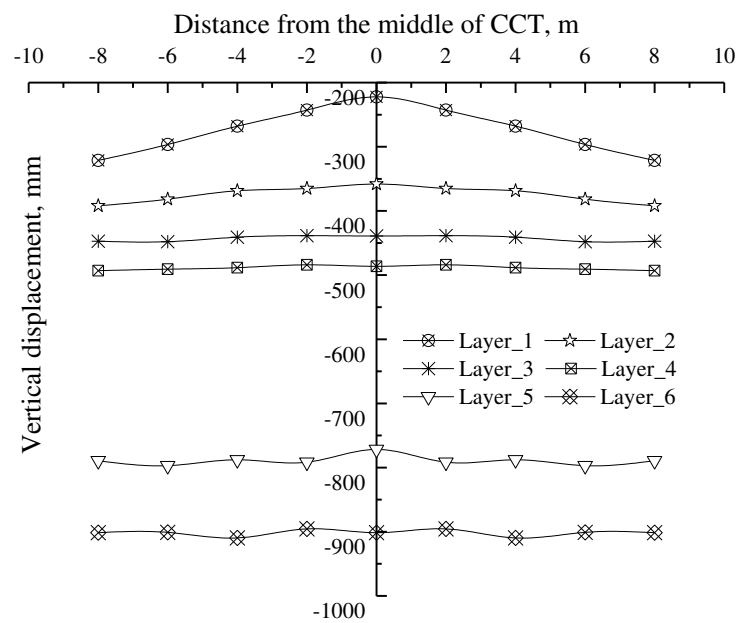

(b)

Fig. 11 Vertical displacement of each layer: (a) not considering creep and (b) considering creep of backfill soil.

\subsubsection{Surface settlement}

The cumulative displacement of each layer of the high backfill soil is eventually detected by the surface settlement. Fig. 12 presents the variation in the settlement of the backfill soil at the surface (Section $\mathrm{H}-\mathrm{H}$ ). The results show that, when the creep of the backfill soil is not considered, the surface settlement at the axis of the CCT (Section $\mathrm{H}-\mathrm{H})$ is slightly greater than on both sides (Section $\mathrm{H}-\mathrm{H}$ ), which is basically close to $-65.8 \mathrm{~mm}$. When the creep of the backfill soil is 
considered, the surface settlement increases from $-816.73 \mathrm{~mm}$ to $-874.83 \mathrm{~mm}$ at the corresponding locations. The increment of the settlement accounts for $92 \%$ of the total settlement. In addition, the maximum surface settlement is $874.8 \mathrm{~mm}$ whereas the maximum settlement at Layer_6 is $901.6 \mathrm{~mm}$ (Fig. 11 (b)). Therefore, these results indicate that the maximum settlement occurs just below the surface.

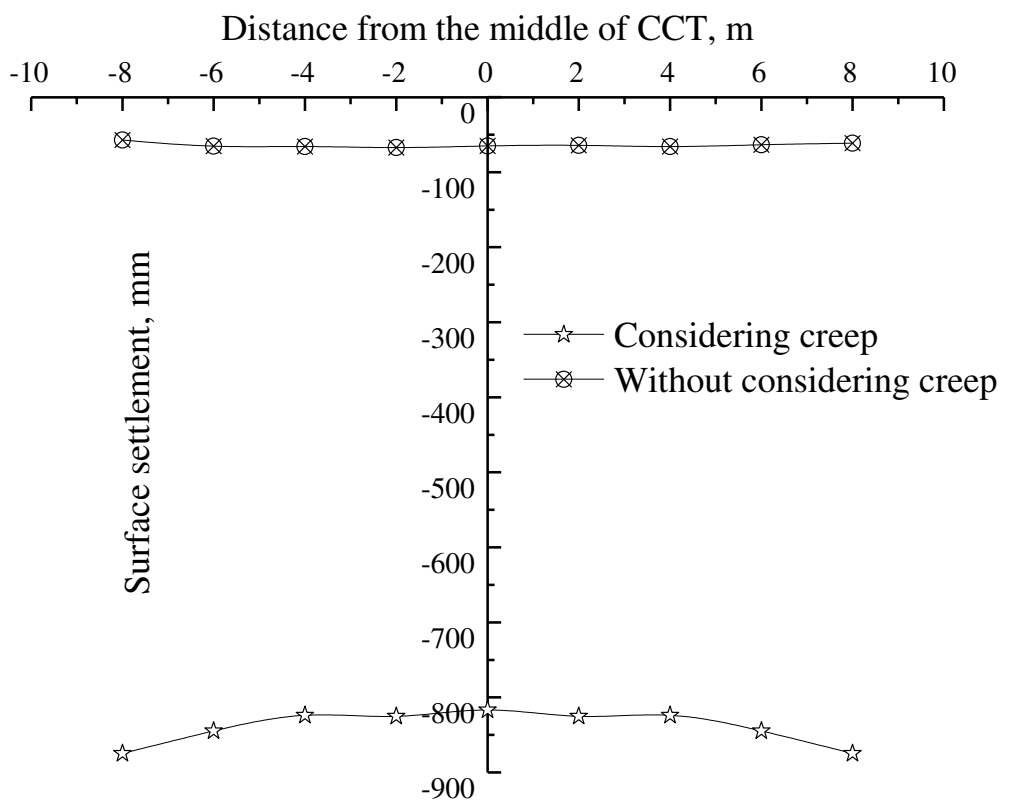

Fig. 12 Surface settlement at Section $\mathrm{H}-\mathrm{H}$.

\subsection{Microscopic analysis of backfill soil particles}

\subsubsection{Porosity and coordination number}

For the numerical simulations, measurement circles were set to obtain the porosity and coordination number for Layer_1 and Layer_3. The porosity represents the ratio of total porosity to the measured circular area. The coordination number represents the average number of active 
contacts per particle body. Therefore, a relatively large porosity always corresponds to a relatively low coordination number. In the PFC2D, the variation in porosity and coordination number can explain the macroscopic behavior of backfill soil from a microscopic perspective.

Fig. 13 presents the variation in the porosity and coordination number curves. Porosity is more pronounced at Section J-J than at Section I-I during all the stages of creep. Also, after the creep becomes stable, differences between Section I-I and Section J-J with respect to microscopic aspects are still evident. These microscopic differences are consistent with the macro performance described in Section 3.2.1, which indicates that the microscopic behavior reflects macroscopic changes at each stage. From the microscopic level, the characteristics of the variations in the curves can be described as follows. In the initial stages from Stage 1 to Stage 4, the relative positions of the soil particles are dynamic and constantly changing, and the structure of the backfill soil changes from looser to denser with the rapid rise in earth pressure, which results in the significant increase in the number of particles in the unit volume and the contacts among the particles to become close. Consequently, the curves for porosity and coordination number fall and rise, respectively. When the creep has stabilized (after Stage 4), the relative positions and contacts among the particles have reached a stable state. 


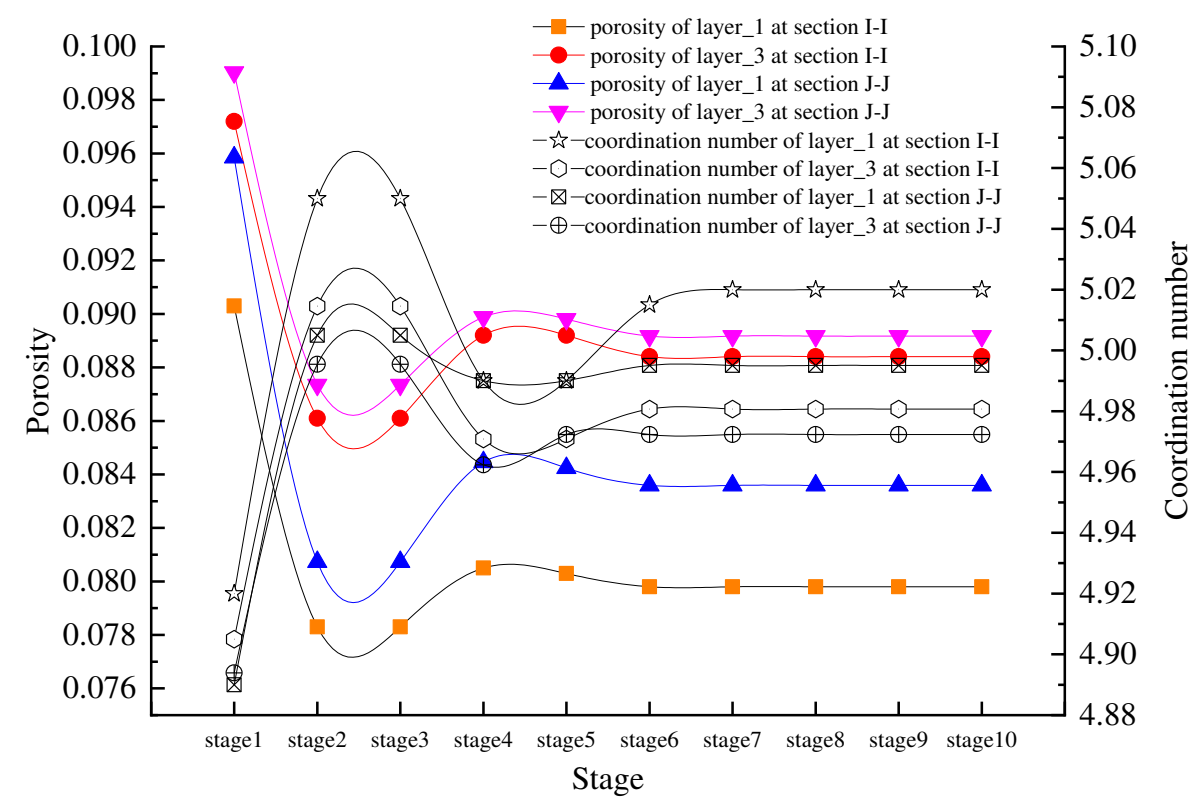

Fig. 13 Porosity and coordination number for different layers

at Sections I-I and J-J.

\subsubsection{Contact force chain}

In the PFC2D, the load that acts on top of the CCT is transmitted through the contacts of the particles, and the distribution of these contact force chains embodies the load transfer characteristics in the soil. Fig. 14 presents the changes in the contact force chains among the soil particles at different stages (without considering the creep of the backfill soil as well as at creep Stage 1, Stage 3, and Stage 10). When the creep of the backfill soil is not considered, the distribution of the contact force chains above the CCT is denser and thicker than on both sides of the CCT, which results in the stress concentration on top of the CCT. Moreover, a few short red lines that represent tension appear immediately above the CCT, which indicates that the particles on top of the CCT are pulled as the particles slide along the surface of the CCT. However, the contact force chains on both sides of the CCT become denser and thicker, and the red lines on top of the CCT disappear with time. After the creep of the backfill becomes stable, the contact force 
chains of each layer become basically uniform. The evolution of the contact force chains reflects the adjustment of the earth's pressure from a microscopic perspective, which is consistent with the macroscopic perspective.

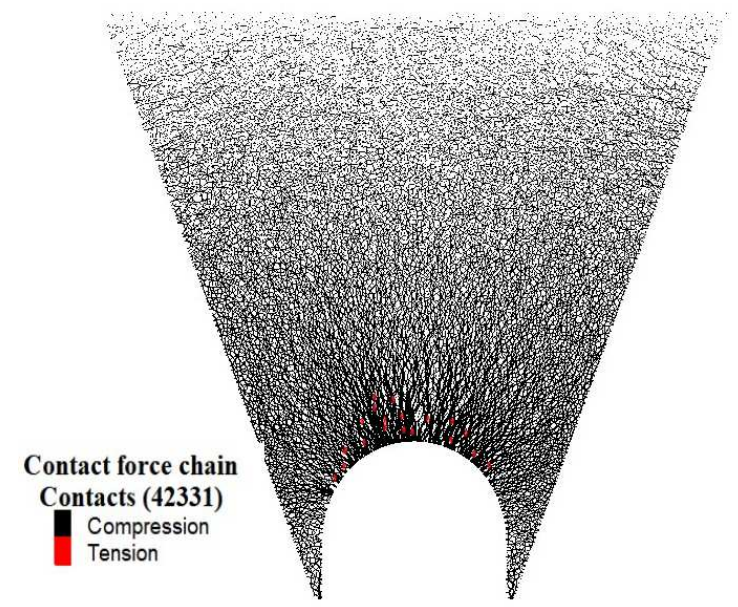

(a)

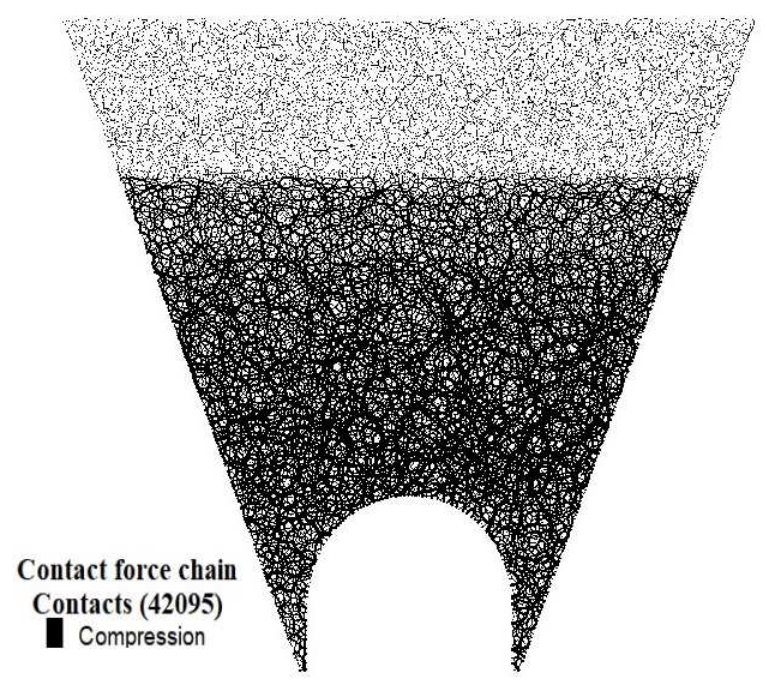

(c)

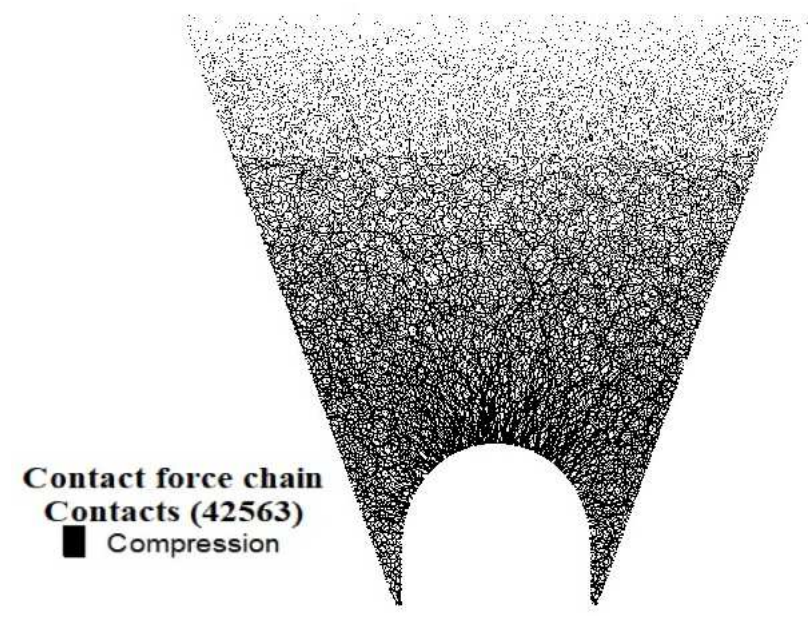

(b)

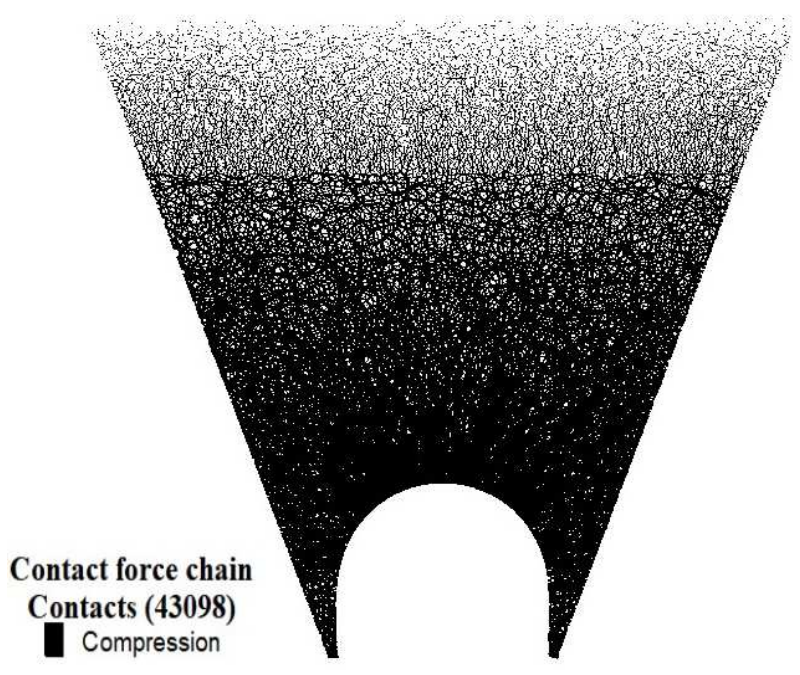

(d)

Fig. 14 Contact force chains for: (a) not considering creep of backfill soil and considering creep at (b) Stage 1, (c) Stage 3, and (d) Stage10. 


\subsubsection{Particle velocity}

Fig. 15 shows the velocity vectors of the soil particles at the different creep stages. The direction of the ball arrows represents the movement direction of the soil particles, and the color of the arrows represents the speed of the soil particle. The Fig. 15 show that the velocity of the particles decreases gradually from Layer_1 to Layer_6 at the different creep stages due to the different earth pressure values. Moreover, the velocity of all the particles decreases over time, mainly because the pores are filled quickly and the contacts among the particles becomes denser, which enhances the interaction effects (nesting and biting) among the particles. The change in velocity further reflects the change in the external pressure of the particles and the porosity between particles.

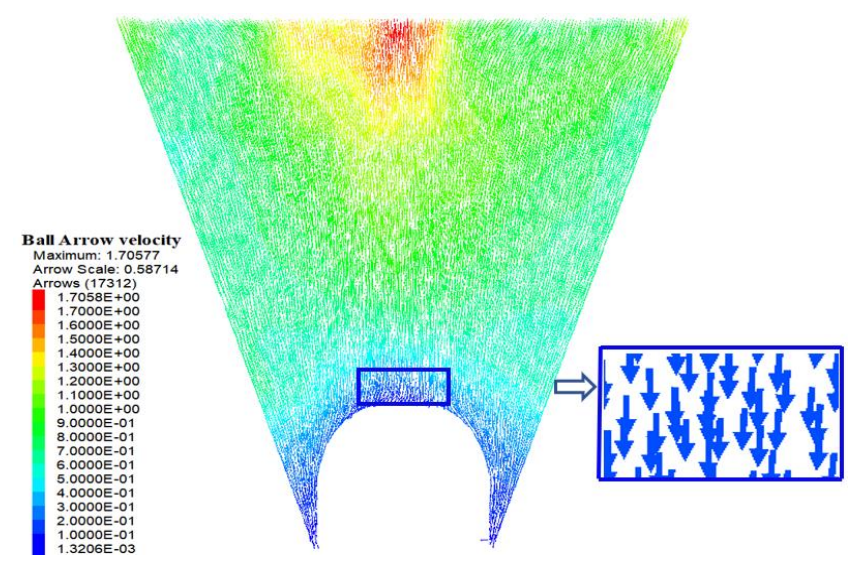

(a)

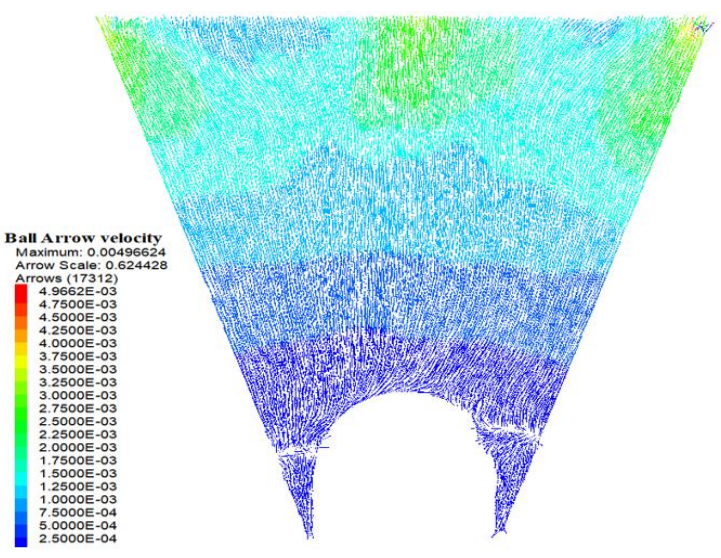

(b) 


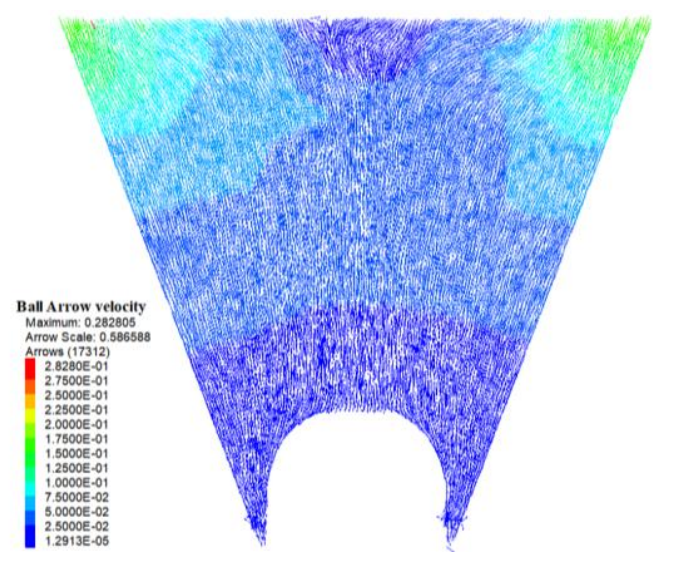

(c)

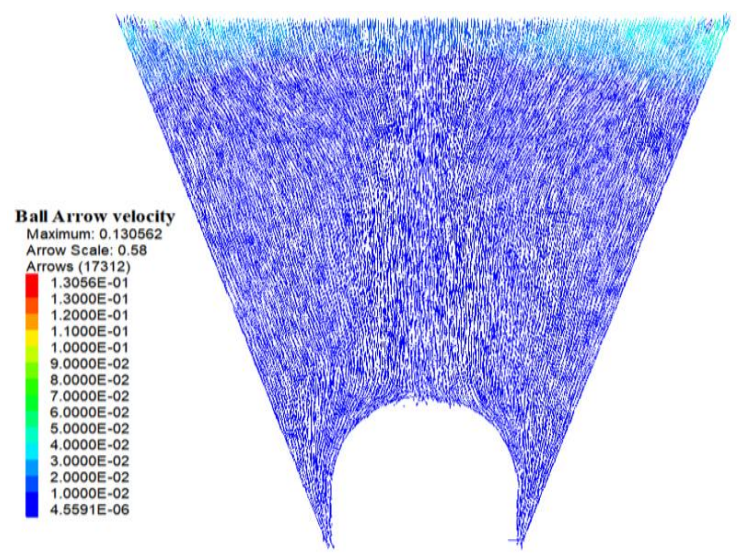

(d)

Fig. 15 Particle velocity vectors for (a) Stage 1, (b) Stage 3, (c) Stage 6, and (d) Stage10.

\section{Discussion}

In HFCCTs, backfill soil creep leads to stress redistribution. In turn, the stress redistribution induces further cycles of soil's primary consolidation and creep. Analysis of the PFC2D simulation results shows that, when the creep of the backfill soil is not considered, the variations in VEP and vertical displacement are consistent with previous research results (Li et al. 2019a, b; 2020a, b, c). When the creep of the backfill soil is considered, the results will change over time. The VEP is redistributed with the creep, and the stress concentration and the slope effect weaken over time. The VEP values change from less than $r h$ to more than $r h$ and finally stabilize at $r h$. Therefore, the maximum VEP that appears during the creep process should be taken as the external load of the HFCCT structure's design. Meanwhile, the vertical displacement increases significantly over time. In fact, the increment of vertical displacement that is due to creep accounts for more than $90 \%$ of the total vertical displacement. The maximum displacement occurs near the slope, leading to the accumulation of rainwater at this point, which penetrates into the ground along the interface, leading to a secondary disaster. Such scenarios should be considered carefully in the later operation 
and maintenance of HFCCTs.

The porosity and coordination of particles adjust over time, the distribution of the contact force chains in each layer gradually becomes uniform, and the velocity of all the particles decreases. The particles may appear to rebound and adjust to the proper position due to their adaptive ability during the creep process, thereby causing the macro performance to materialize as abrupt change, and this phenomenon needs to be considered carefully in HFCCT engineering.

The results of these simulations show that the creep of backfill soil leads to significant changes in VEP and vertical displacement over time, which are phenomena that must not be ignored. However, we only investigated the creep effect of loess with constant physical parameters. Several other important variables that have significant effects on the development of backfill soil creep were not considered, including the degree of saturation and the effect of the groundwater table. These factors should be investigated in future research.

\section{Conclusions}

In this work, PFC2D software was used to carry out numerical analysis to investigate the VEP distribution, vertical displacement, and load transfer mechanisms above an HFCCT that are related to backfill soil creep over time. Several conclusions can be drawn from this study:

(1) The stress surrounding a CCT is redistributed as a result of the creep of the backfill soil. The stress concentration at the center top of the CCT appears to be stable if the creep of the soil is not considered and the value of VEP is less than $r h$. In fact, both the stress concentration and slope effect weaken over time when soil creep is properly considered, but the VEP will increase significantly and eventually equilibrate with geostatic stress, $r h$.

(2) The increase in settlement due to creep can be greater than $90 \%$ of the total settlement. Moreover, the settlement difference between the internal and external soil columns is marked. 
(3) At the microscopic level, the force transmission between soil particles changes over time. The contact force chains become denser and more uniform at each layer due to the creep of the soil, and the particles' velocity decreases gradually. In addition, changes in the porosity and coordination number of the particles are consistent with macro mechanical changes.

\section{Compliance with ethical standards}

Conflict of interest. The authors declare that they have no conflict of interest.

\section{Acknowledgements}

This study was supported by the National Natural Science Foundation of China (51668036, 51868041), the Changjiang Scholars program and Innovative Research Team in the University (IRT_15R29), and the Energy Geomechanics Laboratory at the University of North Dakota, U.S.A.

\section{References}

Bennett, R. M., Wood, S. M., Drumm, E. C., and Rainwater, N. R. (2005). "Vertical loads on concrete box culverts under high embankments." J. Bridge Eng., 10(6), 643-649. DOI: 10.1061/(ASCE)1084-0702(2005)10:6(643).

Binger, W. V. (1947). "Discussion to 'Underground conduits-An appraisal of modern research'.” Proc. Am. Soc. Civ. Eng., 73, 1543-1545.

Chen, B. G., and Sun, L. (2014). "Performance of a Reinforced Concrete Box Culvert Installed in Trapezoidal Trenches.” J. Bridge Eng., 2014, 19(1): 120-130. DOI: 10.1061/(ASCE)BE.19435592.0000494 . 
Chen, Q., Cui, D.S., Wang, J. E., Liu, Q. B. (2020). "Experimental study of creep characteristics of sliding zone soil of Huang tu po landslide under different consolidation stresses.” Rock and Soil Mechanics, 41(5), 1-8 (in Chinese).

Cundall, P. A., Strack, O. D. L. (1999). “Particle flow code in 2 Dimensions [A].” Itasca Consulting Group, Inc.

Dasgupta, A., and Sengupta, B. (1991). "Large-scale model test on square box culvert backfilled with sand.” J. Geotech. Engrg, 117(1), 156-161. DOI: 10.1061/(ASCE)07339410(1991)117:1(156).

Dong, H. K., Tae, S. Y., Yun M. L., and Yu, H. W. (2012) "DEM simulation on soil creep and associated evolution of pore characteristics." Computers and Geotechnics 39 98-106. DOI: 10.1016/j.compgeo.2011.09.003.

Gu, A. Q. (1981). "Investigation of the vertical earth pressure on projecting conduit and underground chamber under a high embankment." Chinese Journal of Geotechnical Engineering, 3(1), 3-15 (in Chinese).

Ge, M. M., Li, N., Zheng, J. G., Zhu, C. H., and Ma, X. D. (2015). "Numerical analysis of the post-construction settlement regularity of loess-high filled embankment based on creep test" Journal of Xi'an University of Technology, 31(03), 295-300+305 (in Chinese). DOI: 10.19322/j.cnki.issn.1006-4710.2015.03.007.

Kim, K., and Yoo, C. H. (2005). "Design loading on deeply buried box culverts." J. Geotech. Geoenviron. Eng., 131(1), 20-27. DOI: 10.1061/(ASCE)1090-0241(2005)131:1(20).

Lai, H. J., Zheng, J. J., Zhang, J., Zhang, R. J., Cui, L. (2014). “DEM analysis of 'soil' -arching within geogrid-reinforced and unreinforced pile-supported embankments." Computer and Geotechnics, 61: 13-23. DOI: 10.1016/j.compgeo.2014.04.007. 
Li, S., Wang, Q. C., Ma, L., Li, J. X., and Li, W. L. (2014). "Model analysis of earth pressure load reduction and soil arch effect for high fill open cut tunnel in loess area", China Civil Engineering Journal, 47(007), 118-125 (in Chinese). DOI: 10.15951/j.tmgcxb.2014.07.040.

Li, S., Ho, I. H., Ma, L., Yao, Y. X., and Wang, C. D. (2019a). "Load Reduction on High-Filled Cut-and-Cover Tunnel Using Discrete Element Method." Computer and Geotechnics, 114, 103149. https://doi.org/10.1016/j.compgeo.2019.103149.

DOI:10.1016/j.compgeo.2019.103149.

Li, S., Ma, L., Ho, I. H., Wang, Q. C., Yu, B. T., and Zhou, P. (2019b). "Modification of Vertical Earth Pressure Formulas for High Fill Cut-and-Cover Tunnels Using Experimental and Numerical Methods." Mathematical Problems in Engineering, Article ID 8257157, 19 p. https://doi.org/10.1155/2019/8257157. DOI:10.1155/2019/8257157.

Li, S., Han, G. Q., Ho, I. H., Ma, L., Wang, Q. C., and Yu, B. T. (2020a). “Coupled Effect of CrossSectional Shape and Load Reduction on High-Filled Cut-and-Cover Tunnels Considering SoilStructure Interaction." International Journal of Geomechanics, 20(7): 04020082. DOI: 10.1061/(ASCE)GM.1943-5622.0001696.

Li, S., Yao, Y. X., Ho, I. H., Ma, L., Wang, Q. C., and Wang, C. D. (2020b). “Coupled Effect of Expanded Polystyrene and Geogrid on Load Reduction for High-Filled Cut-and-Cover Tunnels Using the Discrete Element Method.” International Journal of Geomechanics, 20(6): 04020052. DOI: 10.1061/(ASCE)GM.1943-5622.0001683.

Li, S., Jianie, Y. C., Ho, I. H., Ma, L., Wang, Q. C., and Yu, B. T. (2020c). "Experimental and Numerical Analyses for Earth Pressure Distribution on High-Filled Cut-and-Cover Tunnels.” KSCE Journal of Civil Engineering, (4): 1-7. DOI 10.1007/s12205-020-1693-7. 
Li, Y. G., and Zhang, S. Y. (2008). "Experimental and theoretical study on earth pressure on top of rectangular trench-buried culverts.” Chinese Rock and Earth Mechanics, 29(4), 1081-1086 (in Chinese). DOI: 10.16285/j.rsm.2008.04.049.

Ma, L., Li, S., Ho, I. H., Wang, Q. C., and Yu, B.T. (2020). "Method to Estimate Lateral Earth Pressure on High-Filled Cut-and-Cover Tunnels.” KSCE Journal of Civil Engineering, 24(3), 975-987. https://doi.org/10.1007/s12205-020-1060-8. DOI:10.1007/s12205-020-1060-8.

Marston, A. and Anderson, A. O. (1913). "The theory of loads on pipes in ditch and tests of cement and clay drain tile and sever pipe." Bulletin No. 31, Iowa Engineering Experiment Station, Ames, IA.

Marston, A. (1930). "The theory of external loads on closed conduits in the light of the latest experiments.” Bulletin No. 96, Iowa Engineering Experiment Station, Ames, IA.

McGuigan, B. L., and Valsangkar, A. J. (2010). "Centrifuge testing and numerical analysis of box culverts installed in induced trenches." Can. Geotech. J., 47(2), 147-163. DOI: 10.1139/T09085.

McAffee, R. P., and Valsangkar, A. J. (2008). "Field performance, centrifuge testing, and numerical modelling of an induced trench installation." Can. Geotech. J., 45(1), 85-101. DOI: 10.1139/T07-086.

Ming, X., Juntian, H., and Erxiang, S (2018). "DEM study on the macro- and micro-responses of granular materials subjected to creep and stress relaxation." Computers and Geotechnics 102 111-124. DOI:10.1016/j.compgeo.2018.06.009.

Penman, A.D.M., Charles, J.A., Nash, J.K.T.L., and Humphreys, J.D. (1975). "Performance of culvert under Winscardam.” Geotechnique, 25(4),713-730. 
Spangler, M. G. (1950a). "A theory on loads on negative projecting conduits.” Proc, Highway Research Board, Vol. 30, 153-161, Washington, D.C.

Spangler, M. G. (1950b). "Field measurements of the settlement ratios of various highway culverts." Bulletin 171, Iowa Engineering Experiment Station, Ames, Iowa.

Spangler, M. G. (1948). "Underground conduits—An appraisal of modern research.” Trans. Am. Soc. Civ. Eng., 113(1), 316-345.

Spangler, M. G. (1973). "Long-time measurement of loads on three pipe culverts." Highway Research Record.

Sun, L., Hopkins, T. and Beckham, T. (2011). "Long-term monitoring of culvert load reduction using an imperfect ditch backfilled with geofoam.” Transp. Res. Rec., 2212, 56-64. DOI: 10.3141/2212-06.

Shi, C., Zhang, Q., and Wang, S. N. (2018). Numerical Simulation Technology and Application with Particle Flow Code (PFC5.0).

Trollope, D. H., Speedie, M. G., and Lee, I. K. (1963). "Pressure measurements on Tullaroop dam culvert." Proc., 4th Australia-New Zealand Conf. on Earth Mechanics and Foundation Engineering, In situation of Engineers, Barton, ACT, Australia, 81-92.

Vaslestad, J., Johansen, T. H. and Holm, W (1993). "Load reduction on rigid culverts beneath high fills: Long-term behavior.” Transportation Research Record 1415, Transportation Research Board, Washington, DC, 58-68.

Yang, X. W., and Zhang, Y. X. (2005). "Study on arch action and earth pressure theory for culverts under high embankment.” Journal of Rock Mechanics and Engineering, 24(21), 3887-3893 (in Chinese). 
Yang, M. Z. (2000). "Evaluation of factors affecting earth pressures on buried box culverts." $\mathrm{PhD}$ dissertation, Univ. of Tennessee, Knoxville, Tenn.

Yang, A. W., Zhang Z. J., and Kong L. W. (2014) "Experimental study of creep property of soft clay under different stress conditions.” J. Rock and Soil Mechanics, 35(S2): 53-60. DOI: 10.16285/j.rsm.2014.s2.070.

Zheng, J. J., Chen, B. G, and Zhang, S. B. (2008). "Experimental investigation and numerical simulation of nonlinear earth pressure for trench-buried culverts." Chinese Journal of Geotechnical Engineering, 30 (12), 1771-1777 (in Chinese).

Zhu, C. H., and Li, N. (2015). "Post-construction settlement analysis of loess-high filling based on time-dependent deformation experiments." Rock and Soil Mechanics, 36(10): 3023-3031(in Chinese). DOI: $10.16285 /$ j.rsm.2015.10.037.

Zhang, Y. C., Gao, F., Lv, G. S., Ma, C., and Zhao, Y. (2018). "Numerical simulation of high fill foundation settlement based on creep test of loess." Science Technology and Engineering, 18(30): 220-227(in Chinese).

Ou, X. P., Yan, Z. H., Li, T., Zhu, Y. S., Lyu, N. Z., Guo, H. F., and Lu, C. (2019). "Research on rheological constitutive model of collapsible loess." Journal of Wuhan University of Technology, 43(4), 590-595 (in Chinese). 
Figures

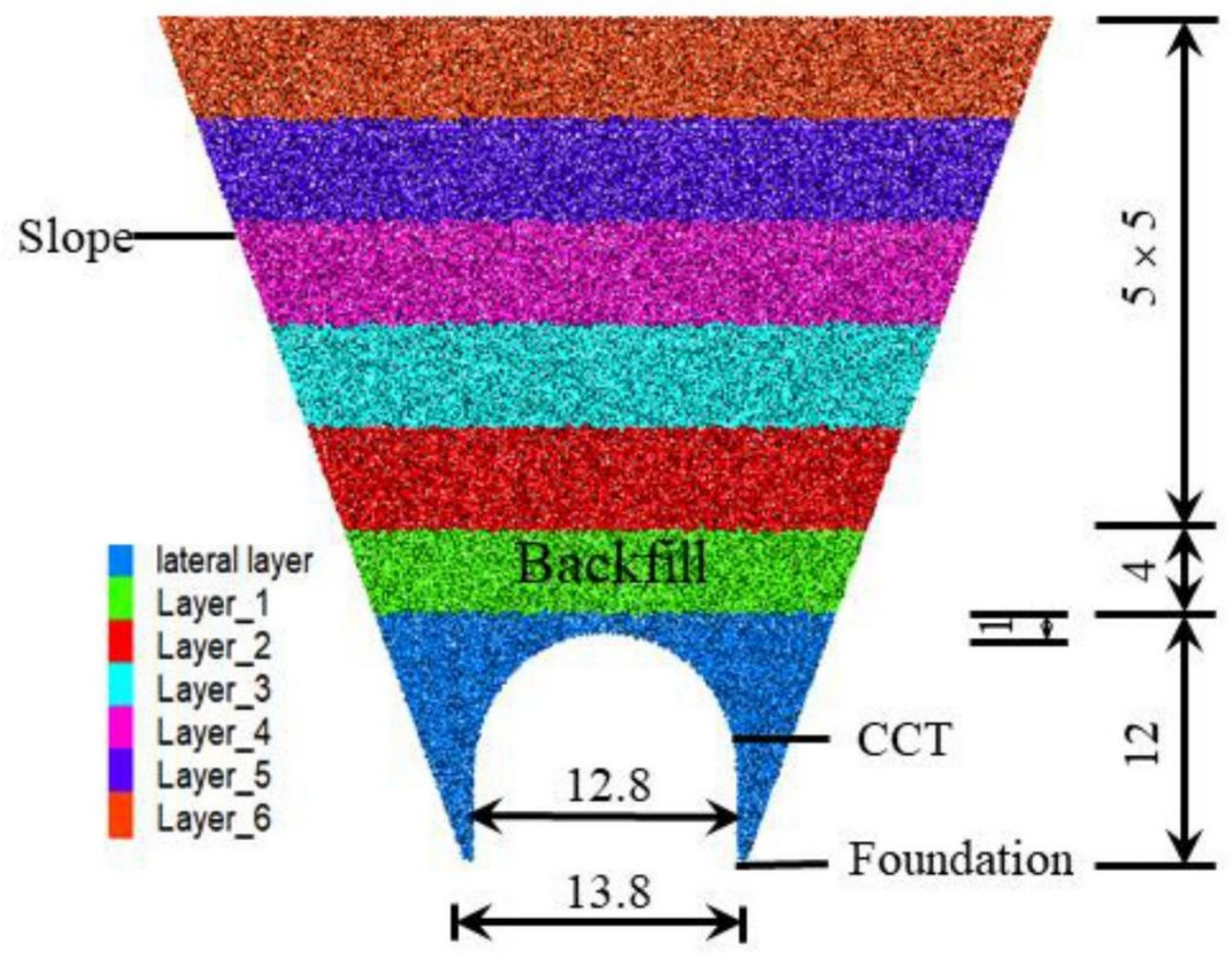

Figure 1

Discrete element model for HFCCT (unit: m). 


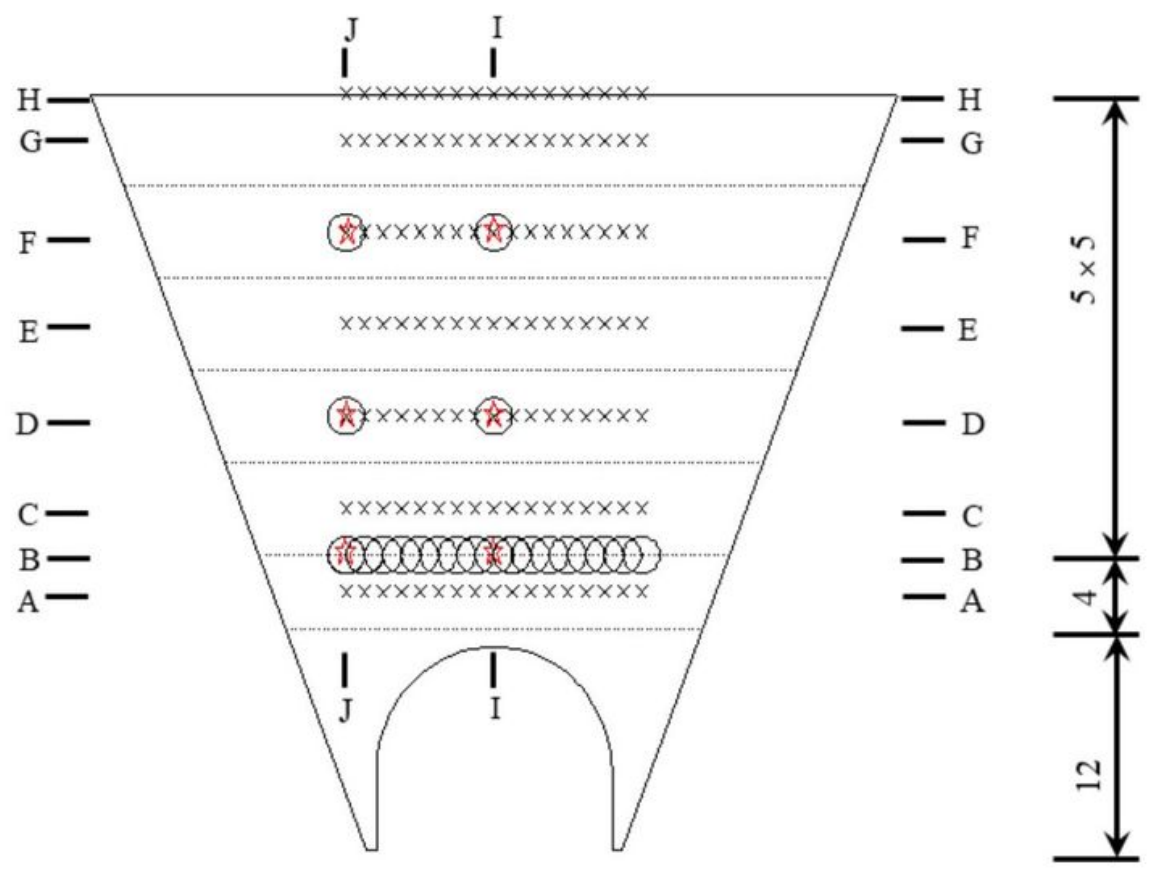

$\mathrm{O}$ Earth pressure measurement circle; $\times$ displacement measurement circle; is porosity and coordination number measurement circle

\section{Figure 2}

Arrangement of measurement circles in model (unit: m).

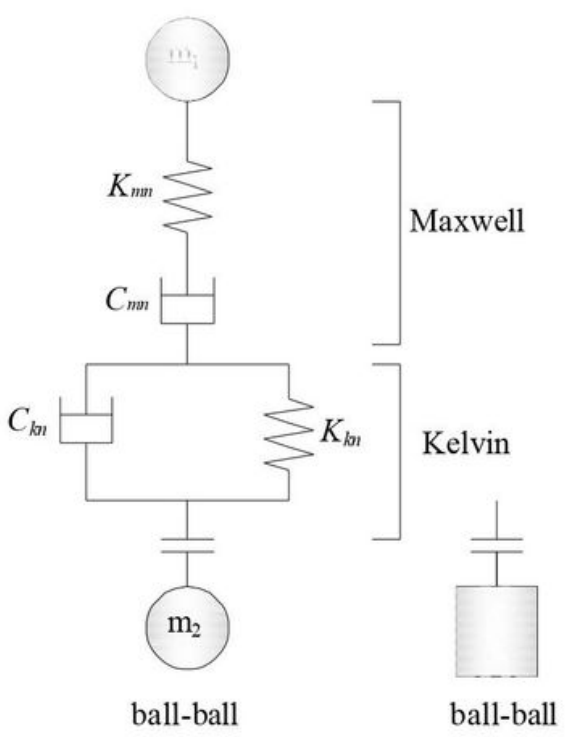

(a)

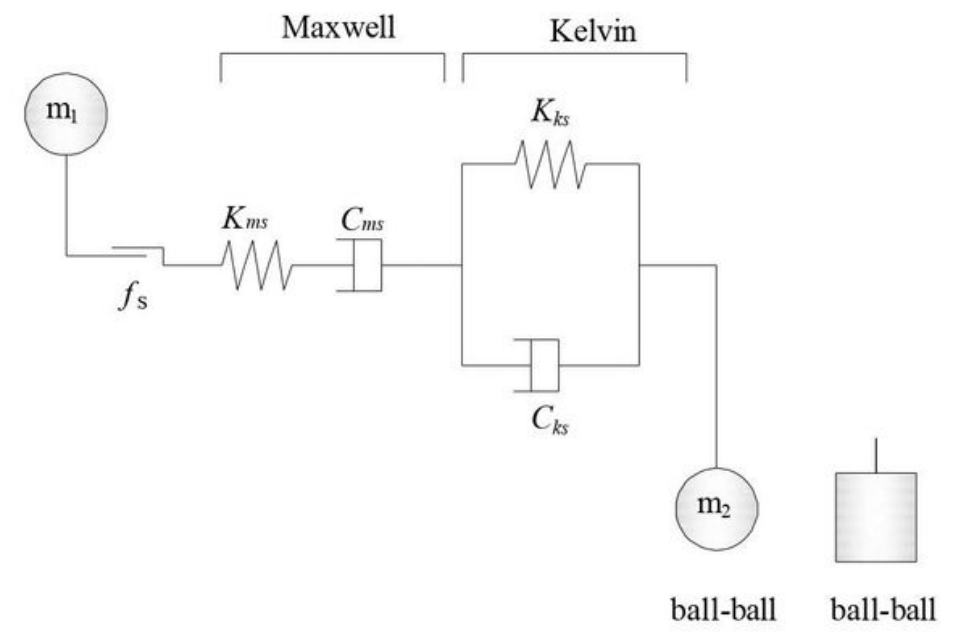

(b) 


\section{Figure 3}

Burgers contact model in PFC2D: (a) normal direction and (b) shear direction.

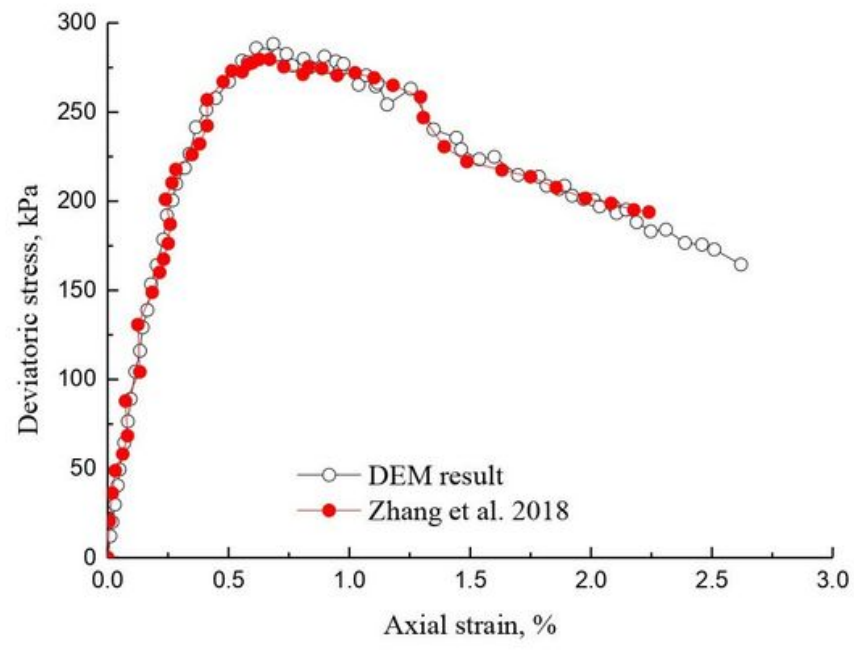

(a)

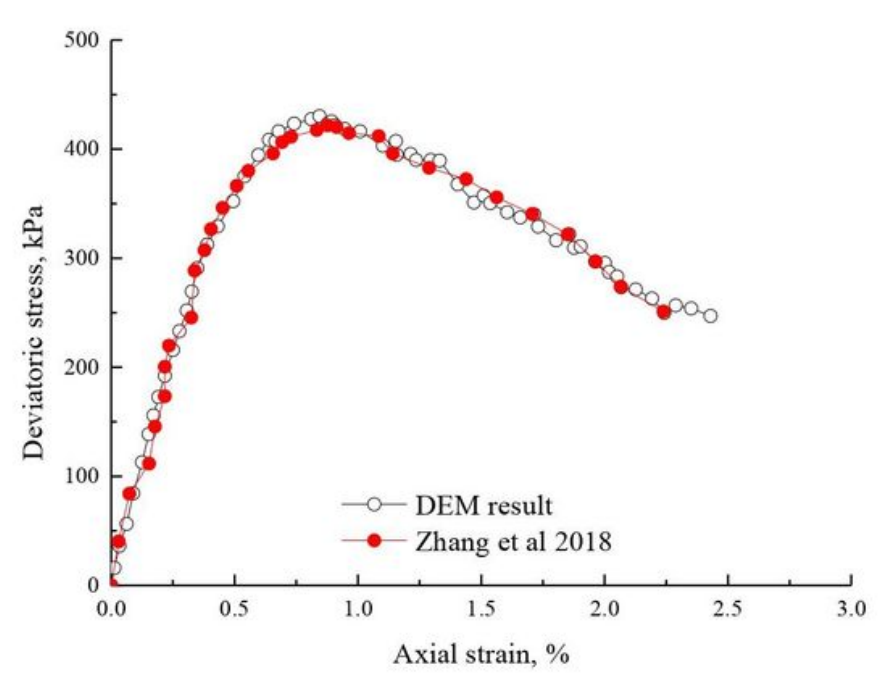

(b)

\section{Figure 4}

Comparison of DEM and Zhang et al. (2018) results for confining stress: (a) $50 \mathrm{kPa}$ and (b) $100 \mathrm{kPa}$. 


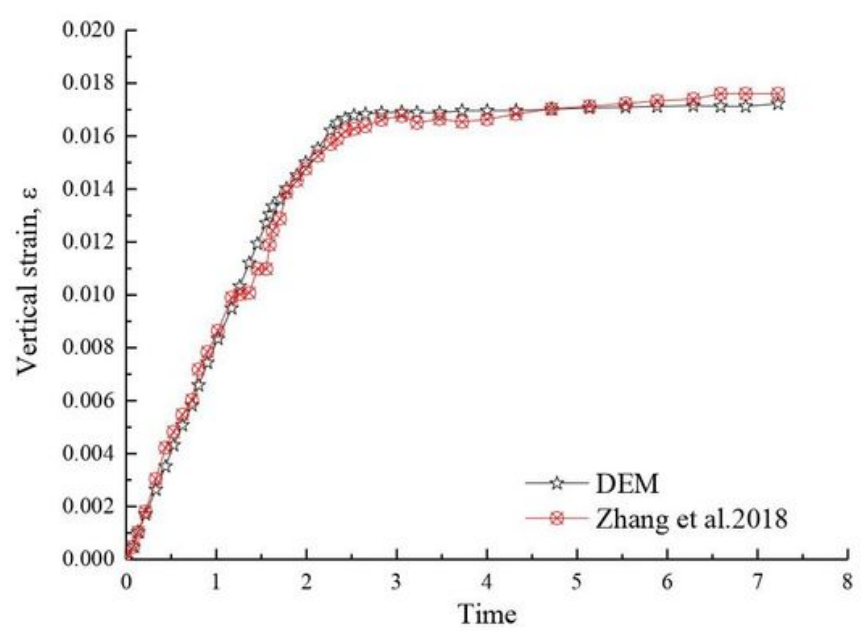

(a)

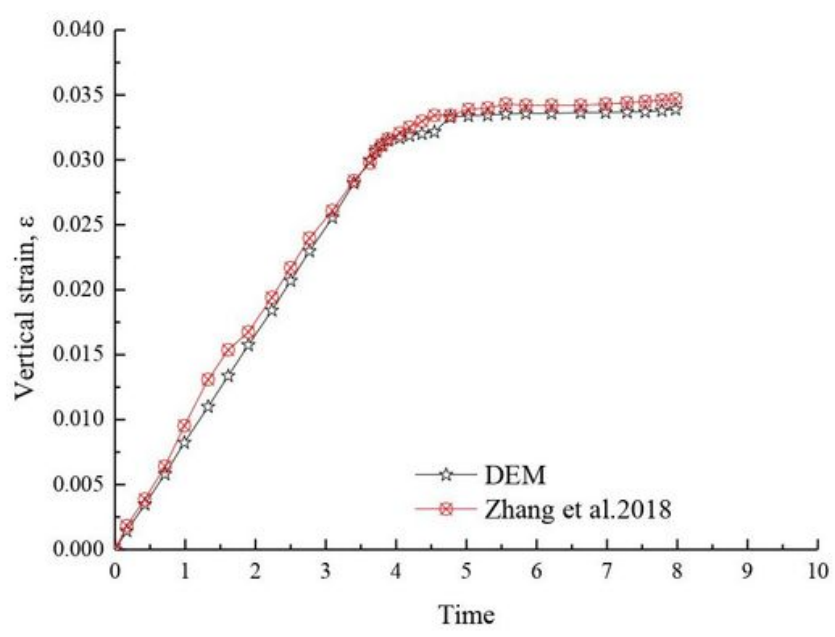

(c)

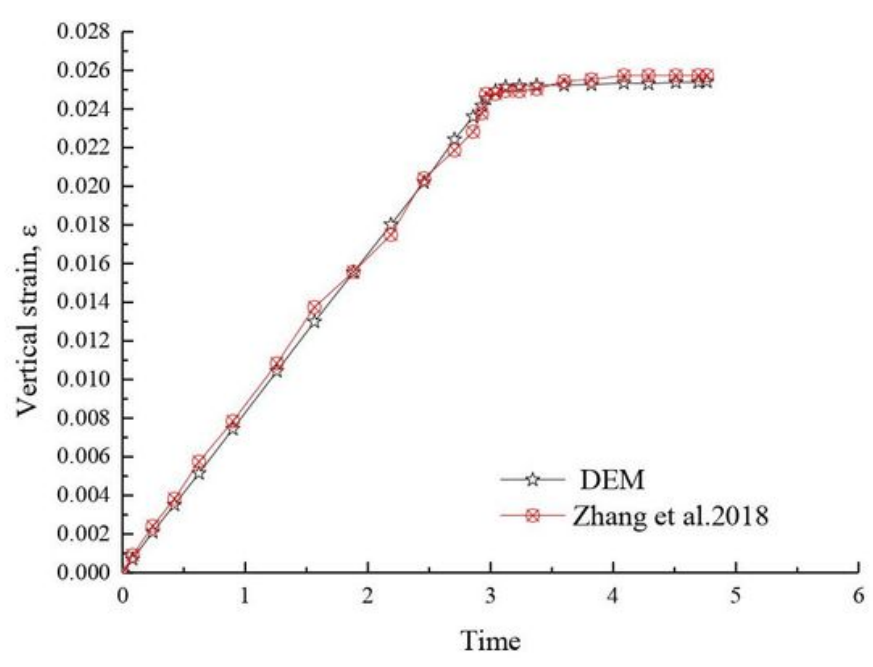

(b)

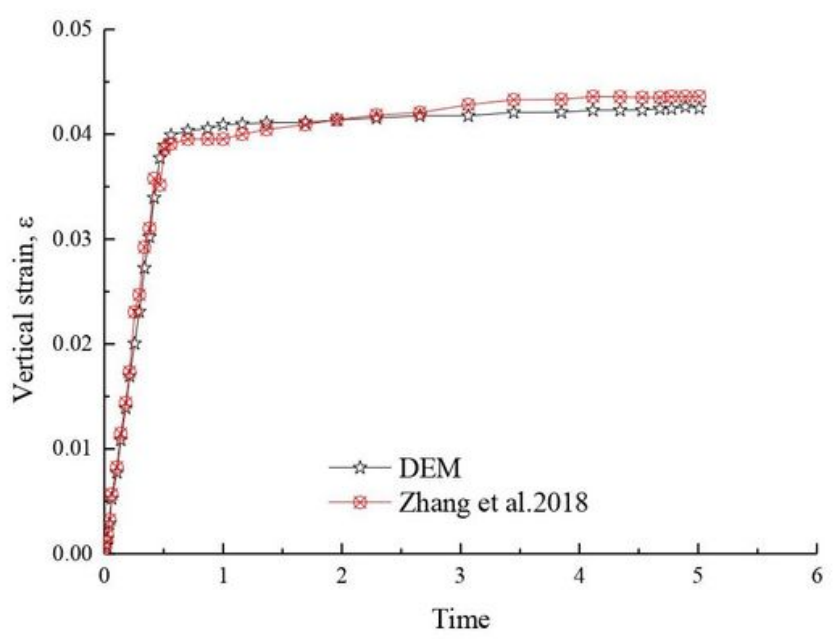

(d)

\section{Figure 5}

Comparison of DEM and Zhang et al. (2018) results under partial initial earth pressure: (a) $110 \mathrm{kPa}$, (b) $200 \mathrm{kPa}$, (c) $265 \mathrm{kPa}$, and (d) $330 \mathrm{kPa}$. 


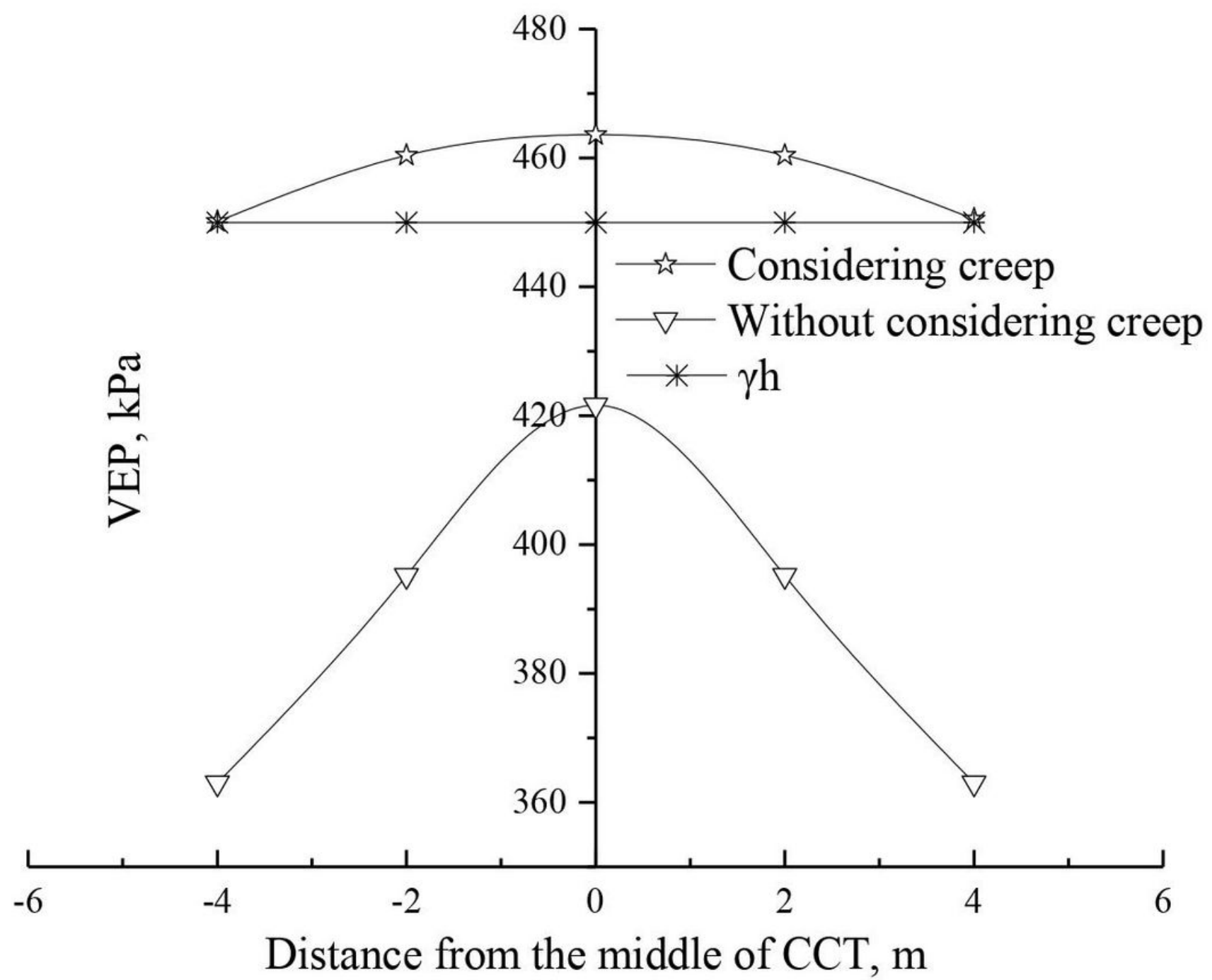

Figure 6

Vertical earth pressure distribution at Section B-B. 


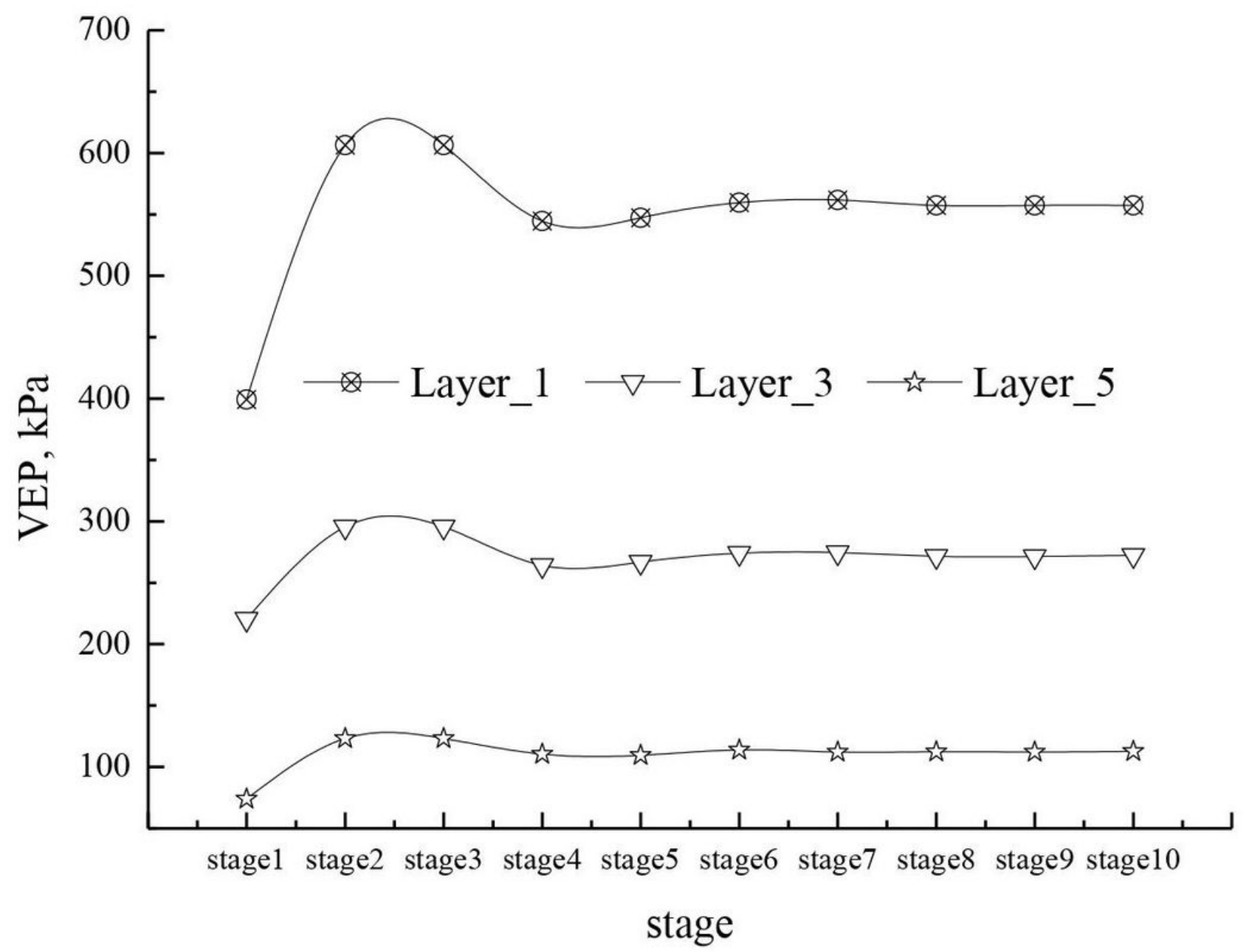

Figure 7

Vertical earth pressure in different layers at Section I-I over time. 


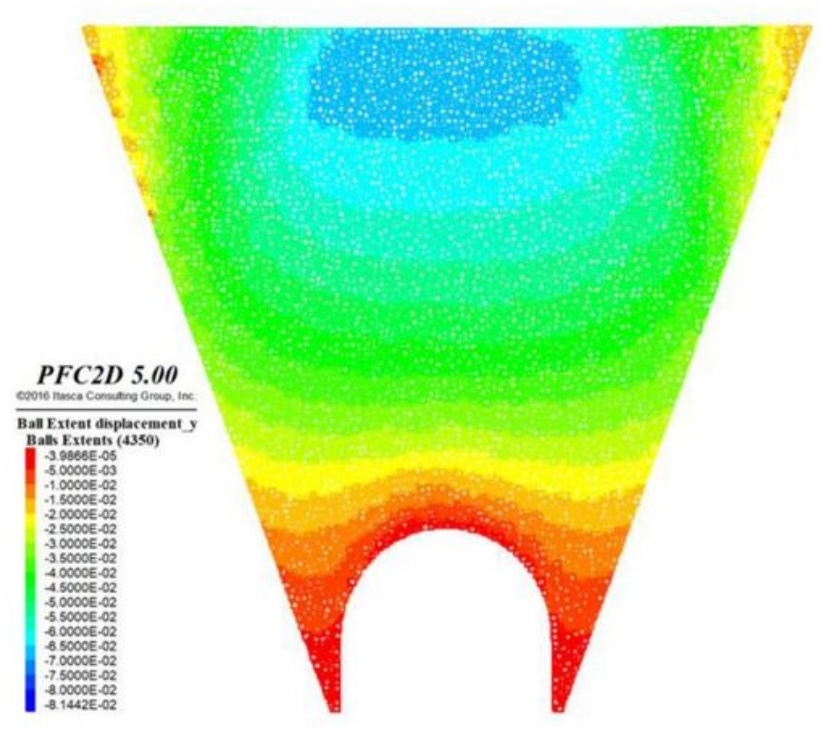

(a)

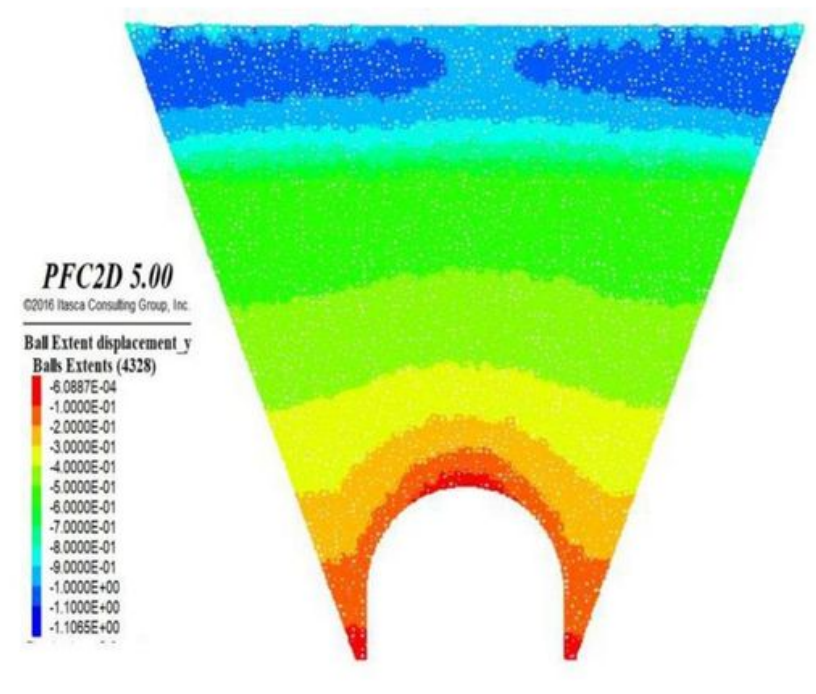

(c)

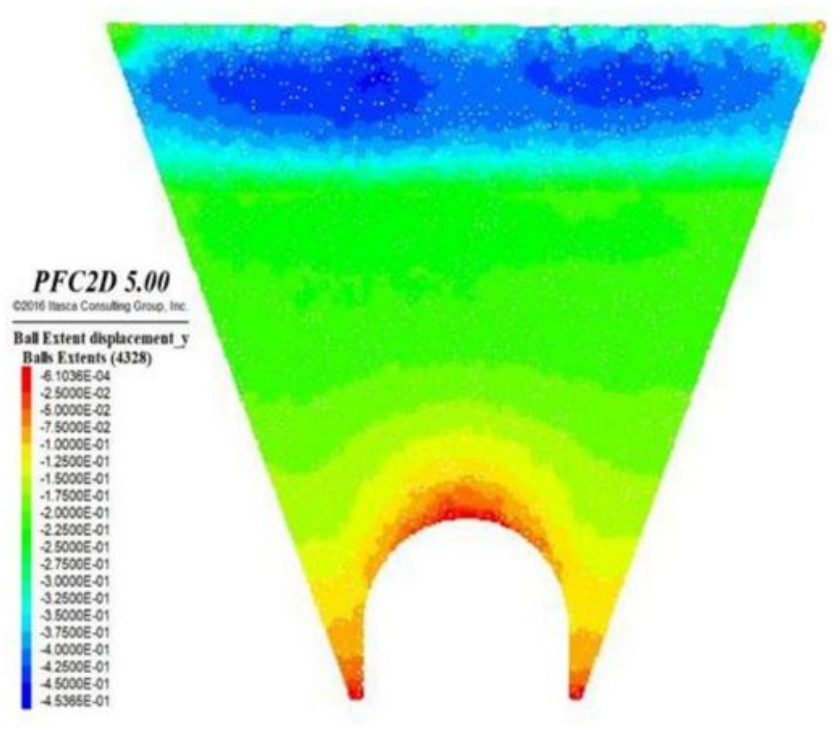

(b)

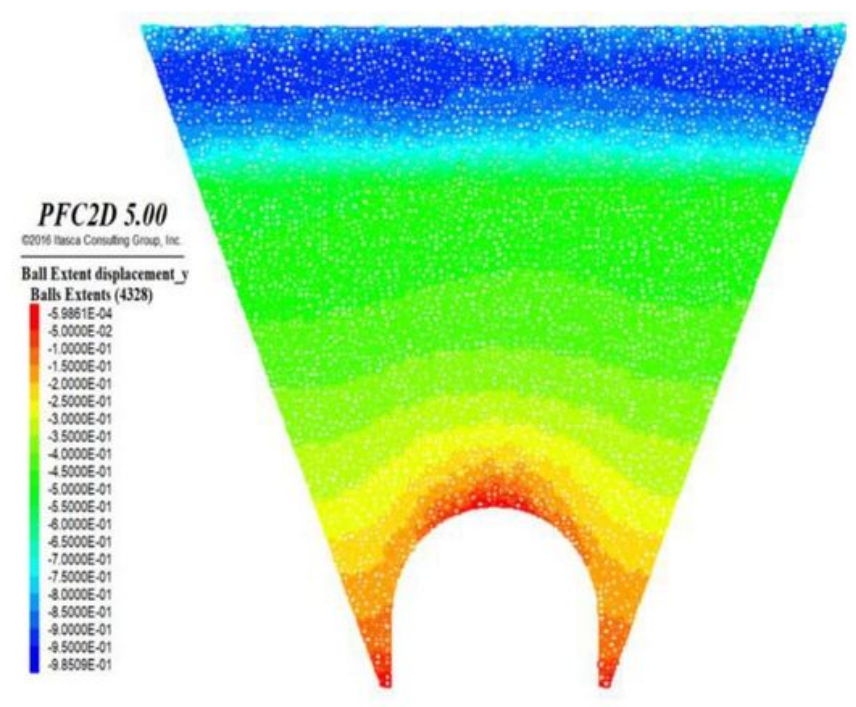

(d)

\section{Figure 8}

Vertical displacement nephrograms of backfill soil: (a) without considering creep of backfill soil; and creep stages at (b) Stage 1, (c) Stage 3, and (d) Stage 10. 


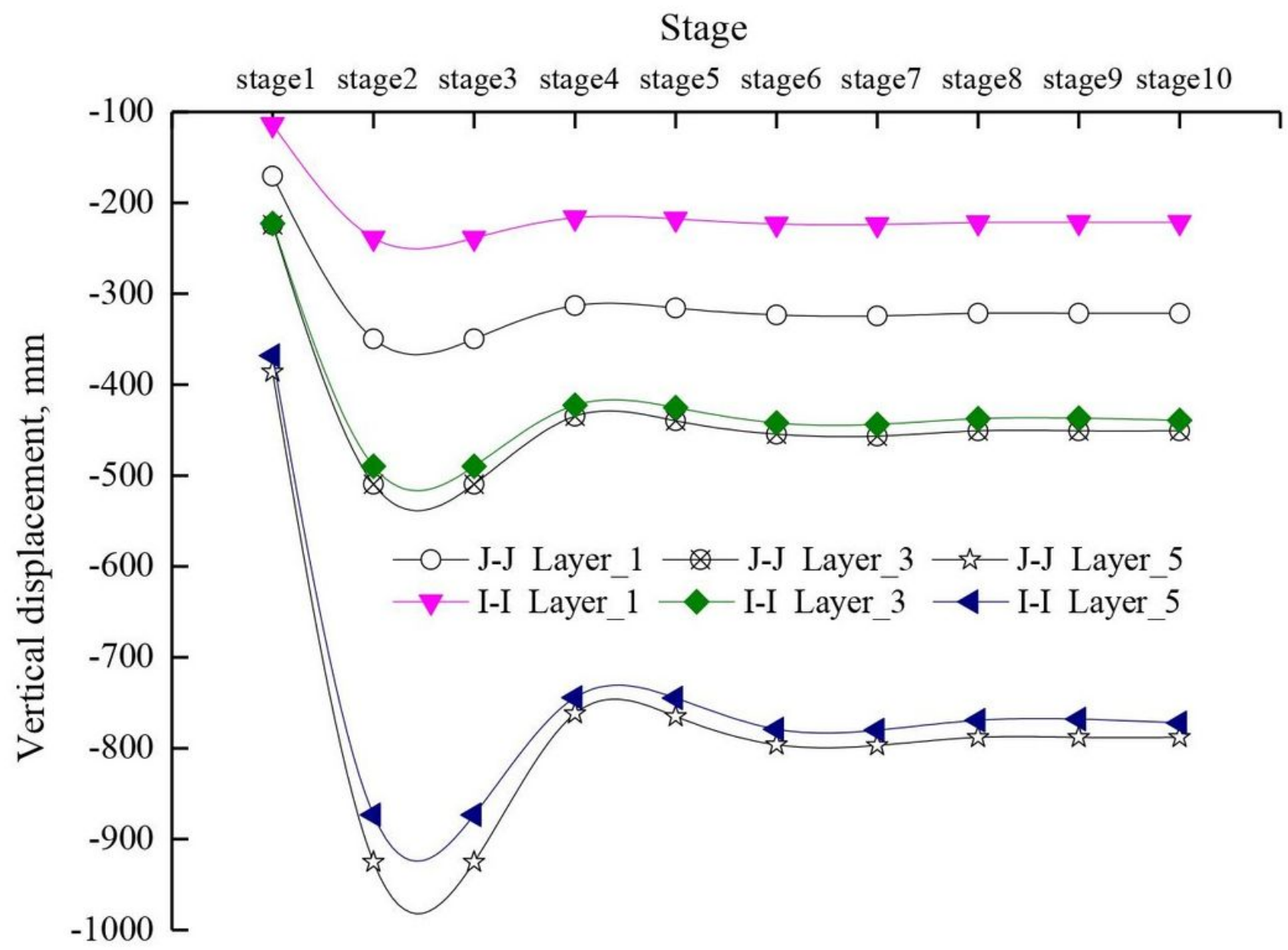

Figure 9

Vertical displacement in different layers at Sections I-I and J-J over time. 
Distance from the middle of CCT, $\mathrm{m}$

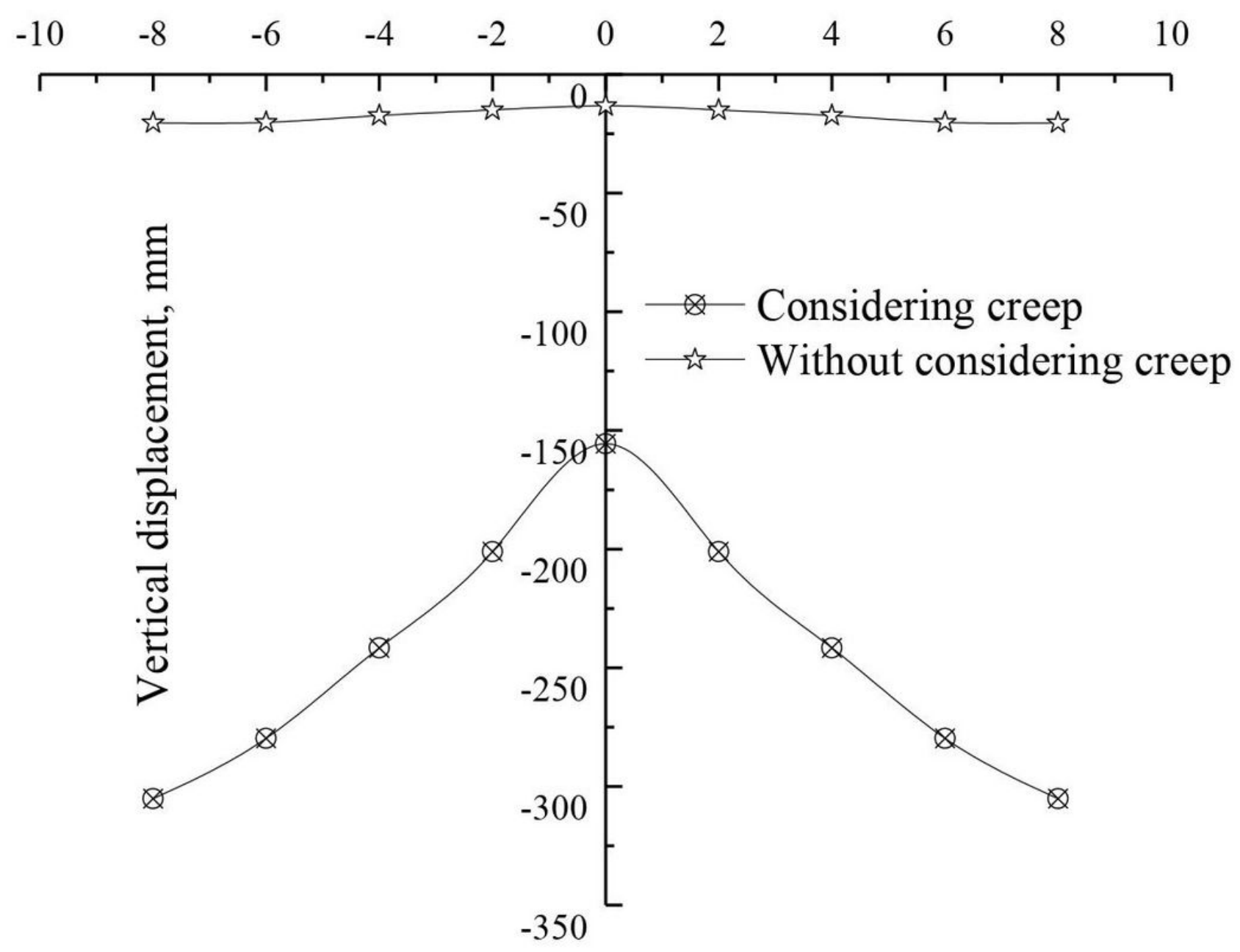

Figure 10

Vertical displacement at Section A-A. 


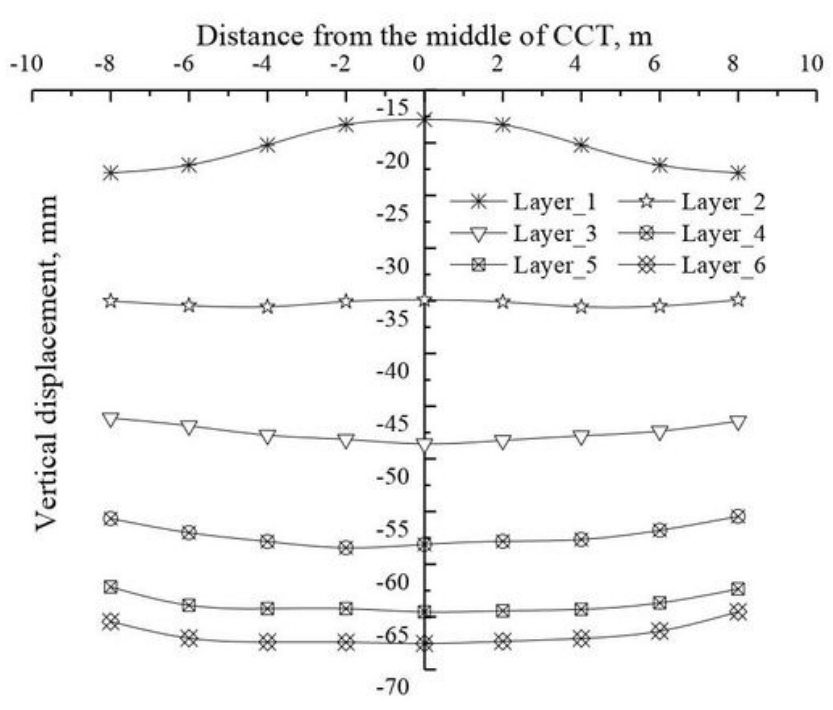

(a)

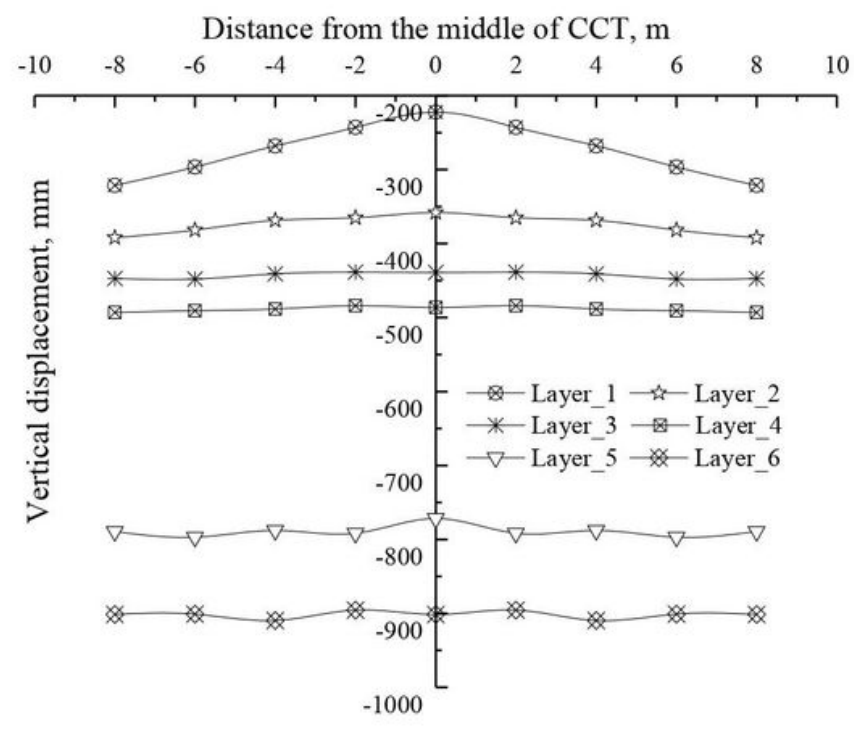

(b)

\section{Figure 11}

Vertical displacement of each layer: (a) not considering creep and (b) considering creep of backfill soil. 


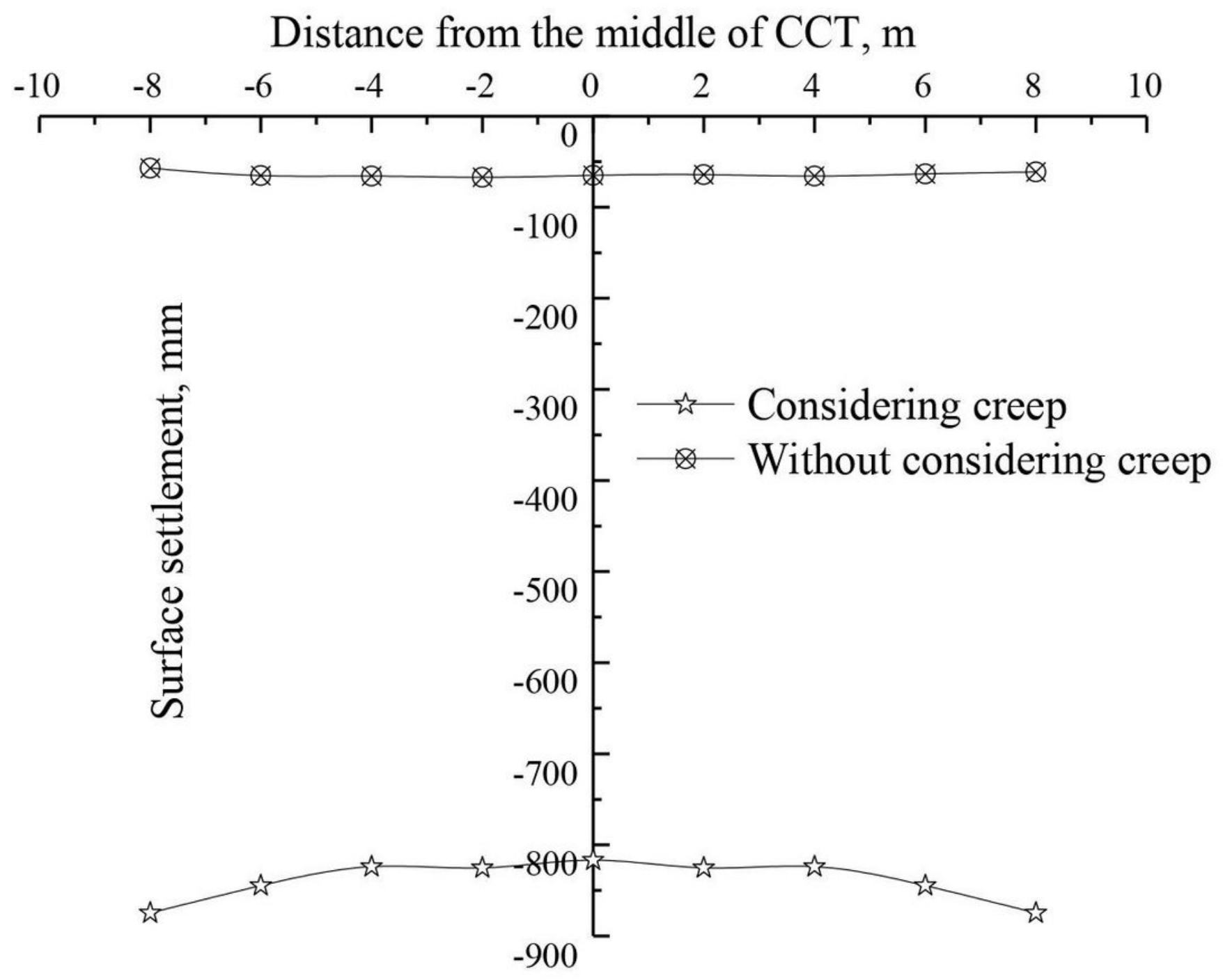

Figure 12

Surface settlement at Section $\mathrm{H}-\mathrm{H}$. 


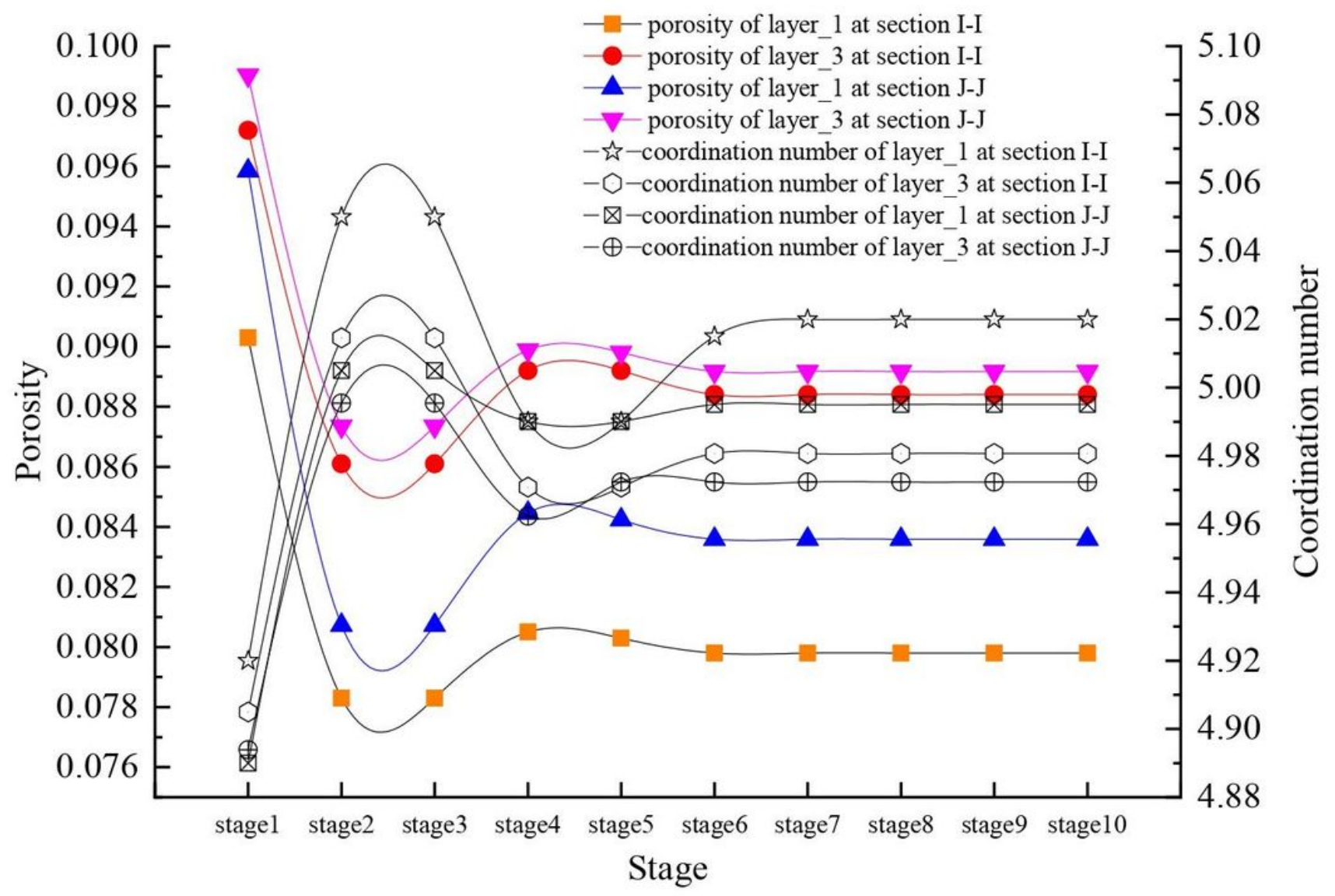

Figure 13

Porosity and coordination number for different layers at Sections $\mathrm{II}$ and $\mathrm{J}-\mathrm{J}$. 


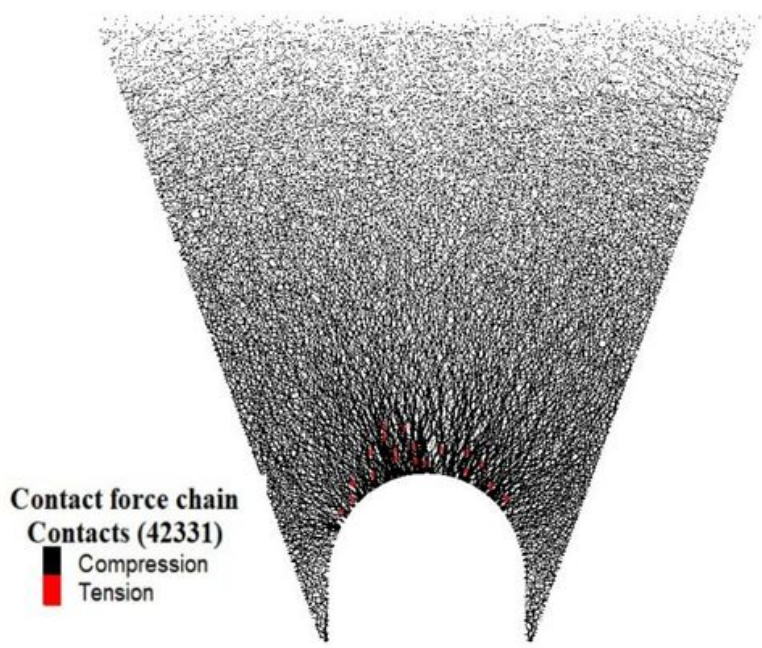

(a)

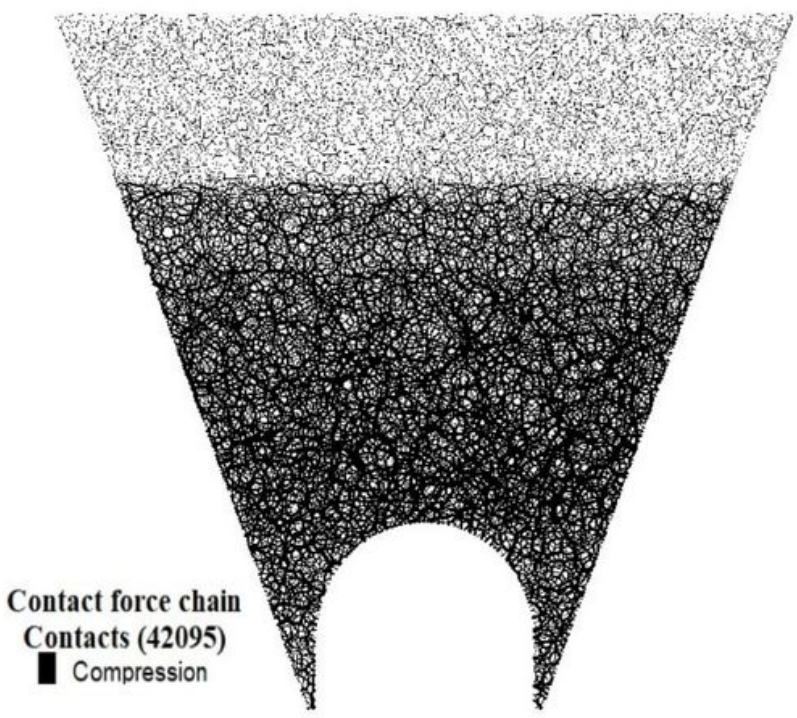

(c)

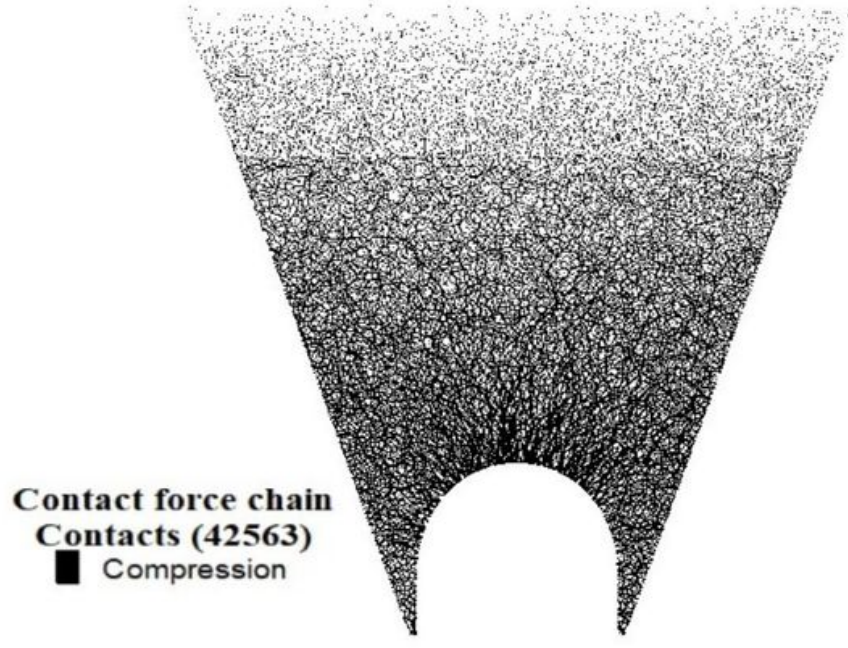

(b)

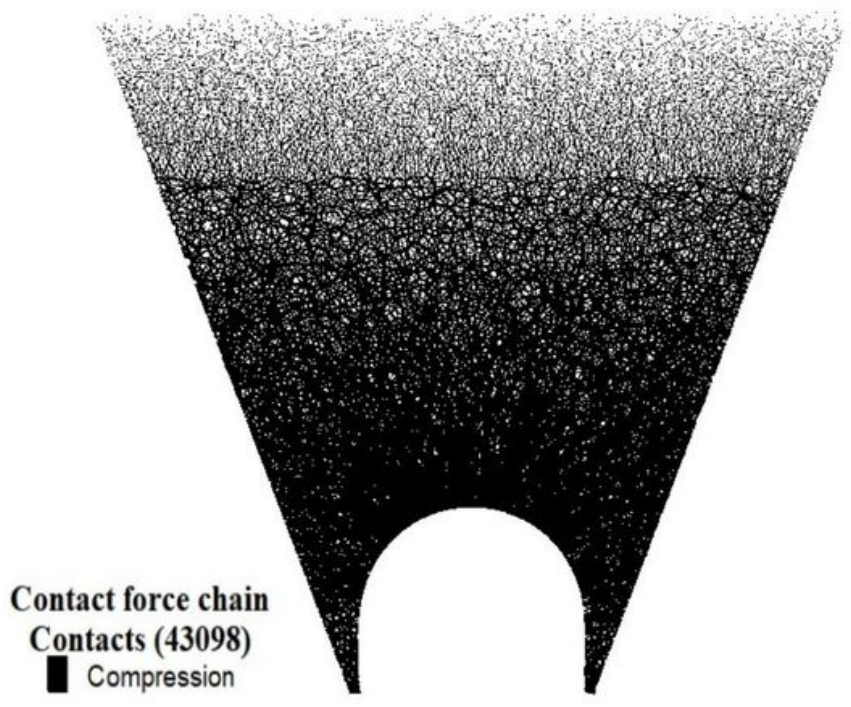

(d)

\section{Figure 14}

Contact force chains for: (a) not considering creep of backfill soil and considering creep at (b) Stage 1, (c) Stage 3, and (d) Stage10. 

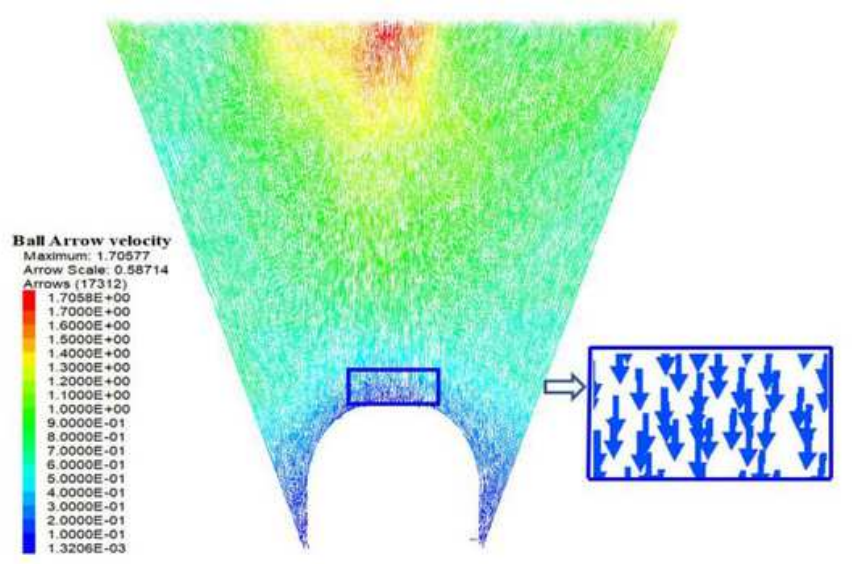

(a)

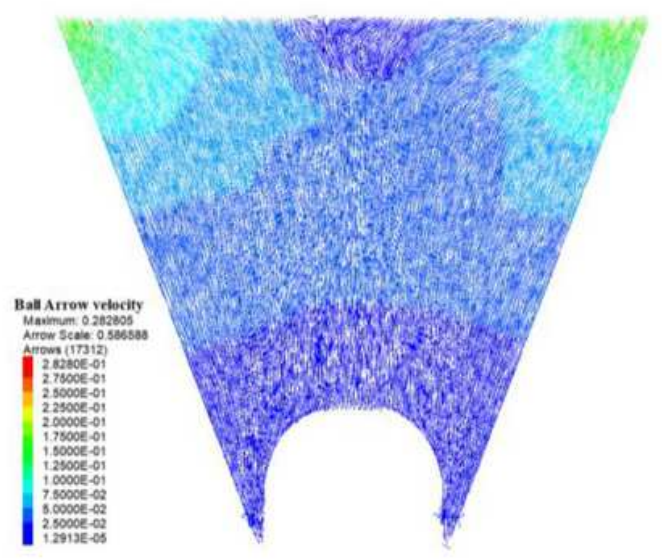

(c)

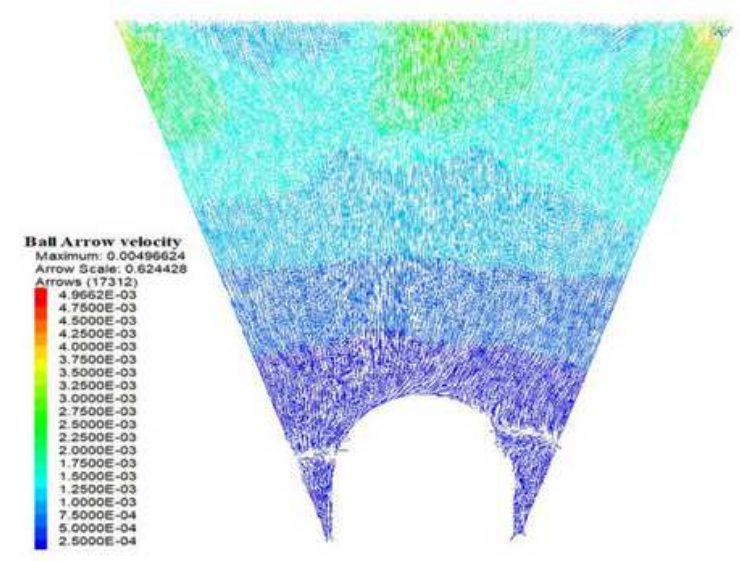

(b)

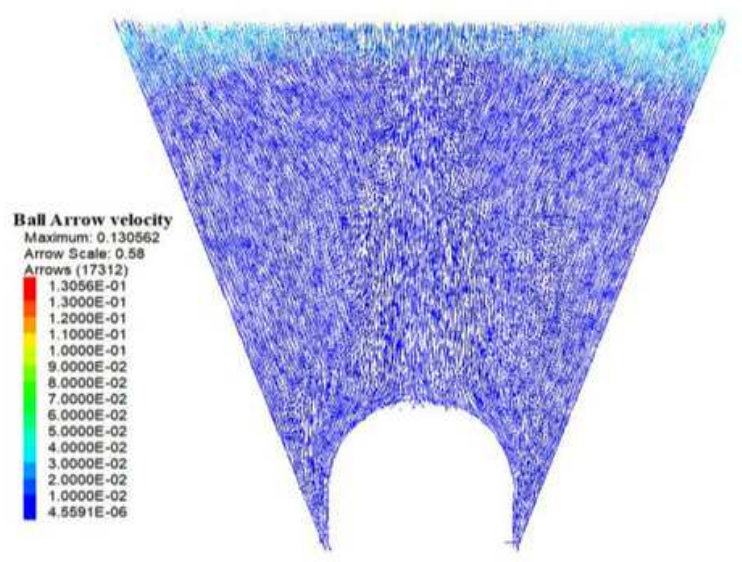

(d)

Figure 15

Particle velocity vectors for (a) Stage 1, (b) Stage 3, (c) Stage 6, and (d) Stage10. 